\title{
Flood triggering in Switzerland: the role of daily to monthly preceding precipitation
}

\author{
P. Froidevaux, J. Schwanbeck, R. Weingartner, C. Chevalier, and O. Martius \\ Oeschger Centre for Climate Change Research and Institute of Geography, University of Bern, Bern, Switzerland \\ Correspondence to: P. Froidevaux (paul.froidevaux@giub.unibe.ch)
}

Received: 12 February 2015 - Published in Hydrol. Earth Syst. Sci. Discuss.: 25 March 2015

Revised: 30 August 2015 - Accepted: 31 August 2015 - Published: 17 September 2015

\begin{abstract}
Determining the role of different precipitation periods for peak discharge generation is crucial for both projecting future changes in flood probability and for short- and medium-range flood forecasting. In this study, catchmentaveraged daily precipitation time series are analyzed prior to annual peak discharge events (floods) in Switzerland. The high number of floods considered - more than 4000 events from 101 catchments have been analyzed - allows to derive significant information about the role of antecedent precipitation for peak discharge generation. Based on the analysis of precipitation times series, a new separation of flood-related precipitation periods is proposed: (i) the period 0 to 1 day before flood days, when the maximum flood-triggering precipitation rates are generally observed, (ii) the period 2 to 3 days before flood days, when longer-lasting synoptic situations generate "significantly higher than normal" precipitation amounts, and (iii) the period from 4 days to 1 month before flood days when previous wet episodes may have already preconditioned the catchment. The novelty of this study lies in the separation of antecedent precipitation into the precursor antecedent precipitation (4 days before floods or earlier, called PRE-AP) and the short range precipitation ( 0 to 3 days before floods, a period when precipitation is often driven by one persistent weather situation like e.g., a stationary low-pressure system). A precise separation of "antecedent" and "peak-triggering" precipitation is not attempted. Instead, the strict definition of antecedent precipitation periods permits a direct comparison of all catchments.

The precipitation accumulating 0 to 3 days before an event is the most relevant for floods in Switzerland. PRE-AP precipitation has only a weak and region-specific influence on flood probability. Floods were significantly more frequent after wet PRE-AP periods only in the Jura Mountains, in the
\end{abstract}

western and eastern Swiss plateau, and at the outlet of large lakes. As a general rule, wet PRE-AP periods enhance the flood probability in catchments with gentle topography, high infiltration rates, and large storage capacity (karstic cavities, deep soils, large reservoirs). In contrast, floods were significantly less frequent after wet PRE-AP periods in glacial catchments because of reduced melt.

For the majority of catchments however, no significant correlation between precipitation amounts and flood occurrences is found when the last 3 days before floods are omitted in the precipitation amounts. Moreover, the PRE-AP was not higher for extreme floods than for annual floods with a high frequency and was very close to climatology for all floods. The fact that floods are not significantly more frequent nor more intense after wet PRE-AP is a clear indicator of a short discharge memory of Pre-Alpine, Alpine and South Alpine Swiss catchments. Our study poses the question whether the impact of long-term precursory precipitation for floods in such catchments is not overestimated in the general perception. The results suggest that the consideration of a 3-4 days precipitation period should be sufficient to represent (understand, reconstruct, model, project) Swiss Alpine floods.

\section{Introduction}

River flooding is one of the most devastating and costly natural hazards in Switzerland (Hilker et al., 2009) and worldwide (Munich Re, 2014). Damaging flood events in the Alps are often caused by high precipitation events that last for several days (e.g., Massacand et al., 1998; Hohenegger et al., 2008; Stucki et al., 2012). However, river discharge during floods can also be influenced by both the spatial and tempo- 
ral characteristics of the precipitation event and by the state of the catchment before the precipitation event, i.e., the antecedent conditions. One of the most important antecedent factors is the total water storage in the form of snow, soil water, ground water and surface water. In particular, the importance of antecedent precipitation for floods has long been emphasized (especially for large catchments). For example, effort is invested in designing continuous hydrological simulations which allow to account for year-long antecedent precipitation time series when assessing discharge extremes (see e.g., Wit and Buishand, 2007, for the Rhine and Meuse basins).

For several recent catastrophic flood events antecedent water storage was important. For example, Reager et al. (2014) point to the importance of a positive water storage anomaly for the 2011 Missouri floods. The floods in June 2013 in central Europe were preceded by above-average precipitation during the second half of May that influenced the flood discharge by presaturating the soils (Grams et al., 2014). Schröter et al. (2015) further show that this exceptional flood event resulted from the combination of non-extraordinary precipitation with extremely high initial wetness. For the floods of 2002 also in central Europe, Ulbrich et al. (2003) describe several intense rainfall episodes in the first half of August that finally led to the extreme discharges. In southern Switzerland, severe flooding of the Lago Maggiore in September 1993 was preceded by a series of high precipitation events in the watershed (Barton et al., 2014). Antecedent conditions might even be relevant for the development of flash floods: Marchi et al. (2010) found that the runoff coefficient, i.e., the fraction of the total rainfall that is routed into runoff, of 58 flash floods in Europe was statistically higher for wetter antecedent precipitation. They however also found that, although flash floods are more frequent after wet antecedent conditions in central Europe, they primarily occur following dry conditions in the Mediterranean region and show no dependence on the antecedent conditions in the Alpine-Mediterranean region. For large Swiss lakes and streams, Stucki et al. (2012) underline the importance of high soil saturation due to excessive water supply by enhanced melt and precipitation over several months for the generation of historical floods.

However, damages in Switzerland often occur when small rivers overflow or when surface runoff occurs outside of river beds (Bezzola and Hegg, 2007). The devastating event of 1993 is a memorable example of how a local river can generate great damages (Hilker et al., 2009). Local floods in Switzerland result from a large variety of hydrological processes (depending on the region, floods may be driven by short but intense showers, continuous rainfall, rain on snow, or snow and/or glacier melt; see Merz and Blöschl, 2003; Helbling et al., 2006; Diezig and Weingartner, 2007). Defining the influence of antecedent precipitation for this large variety of flood types is a complex task. A modeling study by Paschalis et al. (2014) showed that soil saturation can play a paramount role in mediating the discharge response of a small Pre-Alpine catchment. The initial conditions also significantly affect flash flood forecasting in the Southern Swiss Alps (Liechti et al., 2013). However, Norbiato et al. (2009) found that the impact of initial moisture conditions on the runoff coefficient during floods is important only for catchments with intermediate subsurface water storage capacity; i.e., the role of initial moisture conditions is negligible for catchments with either very large or very small storage capacity. Also, reports from Ranzi et al. (2007) on observed floods in mesoscale Alpine catchments with relatively shallow and permeable soil layers conclude that "... values of antecedent precipitation do not dramatically affect the resulting runoff coefficient, at least during major floods. This indicates a smaller sensitivity to initial soil moisture conditions than generally assumed ...".

A better understanding and quantification of the role played by antecedent precipitation in the development of floods is crucial for flood hazard management for two reasons:

i. Because future flood frequency changes might depend on the role of antecedent precipitation. Future changes in precipitation for Switzerland are still uncertain $(\mathrm{CH} 2011,2011)$ but general tendencies can be derived from the projections. In summer, the most important season for Alpine floods, a clear decrease in mean precipitation (due to drier soils) is expected to be accompanied by a weak increase in extreme daily precipitation (due to warmer air, see Rajczak et al., 2013). Thus, depending on whether short-term or long-term precipitation is more important for floods, flood frequency might increase or decrease in the future.

ii. Due to the relatively long residence time of water in catchments with significant moisture storage capacity, information regarding the current moisture state can help to improve medium-range flood forecasting. Identifying catchments where the amount of antecedent precipitation is particularly determinant for floods may help to determine critical regions where an efficient use of that information is primordial for flood forecasting systems. For example, it is now possible to derive water storage information from satellite data, and Reager et al. (2014) demonstrate a great potential for warning systems at weekly to seasonal lead times.

Here, we do not aim to quantify the role of antecedent precipitation by calculating runoff coefficients like e.g., in Ranzi et al. (2007), Merz and Blöschl (2009), Norbiato et al. (2009) or Marchi et al. (2010). Instead, following the idea of large sample hydrology (e.g., Gupta et al., 2014), we make use of two extensive networks of rain gauges and river discharge stations to derive robust statistics from an important number of catchments and events. The underlying hypothesis is that if a period of antecedent precipitation influences the ampli- 
tude of peak discharges, floods should be significantly more frequent after wet conditions during that period provided that a sufficient sample of events is investigated. The following questions are addressed in particular for different precipitation periods before floods (e.g., 0-1 days, 3-14 days before floods):

i. In the past 50 years, have floods in Switzerland been significantly more (or less) frequent after wet conditions during that period?

ii. If they were more frequent, can we define catchment properties that determine whether and how strongly that period influences flood probability?

iii. Did extreme floods follow wetter antecedent conditions than smaller discharge peaks?

iv. Which precipitation accumulation period is most closely related to flood occurrence?

v. How many days of antecedent precipitation are relevant for floods?

We aim to explicitly separate short-range and long-range antecedent precipitation and thus discuss the temporal separation of different precipitation accumulation periods. The analysis comprises thousands of annual maximum discharge events in a large sample of catchments representative of the various hydrological regions of Switzerland. This analysis is unique for Switzerland with regard to the number of floods considered and, to our knowledge, also unprecedented worldwide.

\section{Data}

The events analyzed in this study are 4257 annual maximum instantaneous discharge measurements (called floods hereafter). They were recorded at 101 stations during the period 1961 to 2011 . The data are provided by the Swiss Federal Office of the Environment (FOEN) ${ }^{1}$. The stations measure water level from which a discharge value is obtained through a rating curve that is based on regular discharge measurements. In the case of extreme floods, the discharge values have been manually checked and, if required, have been corrected by hydraulic modeling and expert judgment. All annual maximum discharge events are denoted HQ hereafter. HQs exceeding the 5-year and the 20-year floods will be denoted HQ5 and HQ20, respectively. Note that HQs of estimated return periods of more than 100 years have been recorded in the last decades. Here those floods are simply included in the HQ20 sample (return period larger than 20 years). The distinction of higher return periods than 20 years is avoided in

\footnotetext{
${ }^{1}$ http://www.bafu.admin.ch/index.html?lang=en
}

order to maintain a large sample size. Empirical return periods have been used for simplicity. The empirical return period of a HQ is given by the length of the time series divided by the rank of the HQ (in decreasing order of discharge).

We use gridded daily precipitation accumulations constructed from interpolation of a dense network of rain gauges (see Frei and Schär, 1998). The daily sums (from 06:00 to 06:00 UTC) are available on a 0.02 by 0.02 degrees grid covering the Swiss territory for the period 1961-2011 (hereafter RhiresD, see MeteoSwiss, 2011). The number of gauges varies from approximately 400 to 500 throughout this time period. The effective resolution of the data set, given by the typical inter-station distance, is approximately $15-20 \mathrm{~km}$. Some of the smallest catchments investigated here may not contain any rain gauge but the results from Sect. 4.4 show that the flood-relevant precipitation is adequately captured in each catchment.

\section{Methods}

\subsection{Selection and classification of catchments}

We selected 101 catchments based on the following criteria:

i. the discharge time series must cover at least 20 years during the period 1961-2011;

ii. the catchment must be larger than $10 \mathrm{~km}^{2}$ and its area must be covered $>90 \%$ by the precipitation data set;

iii. the possible human influence on the HQs must be minimal;

iv. a homogeneous representation of the Swiss territory is ensured and multiple counting of basins, i.e., small catchments located in larger catchments, is minimized.

The selected catchments were subdivided according to their size into microscale catchments (Micro, 10$100 \mathrm{~km}^{2}$ ), mesoscale catchments (Meso, 100-1000 km²) and macroscale catchments (Macro, $>1000 \mathrm{~km}^{2}$ ). Catchments within the same size category never overlap spatially, but Micro catchments can be contained in Meso and Macro catchments and Meso catchments in Macro catchments.

Assessment of human influence on peak discharges (e.g., hydropower dams and/or discharge regulation) requires detailed knowledge about water management in each catchment. Some of this information is available within the Hydrological Atlas of Switzerland (see table of plate 5.6 from Aschwanden and Spreafico, 1995). Only Micro and Meso catchments with no or low human influence were selected. Some human influence was tolerated for Macro catchments. Discharge is regulated at the outlets of the majority of large Swiss lakes and the lake outlet stations are analyzed separately (hereafter "Lake Outlets"). Karstic catchments with very complex underground flow were removed based on expert knowledge. 


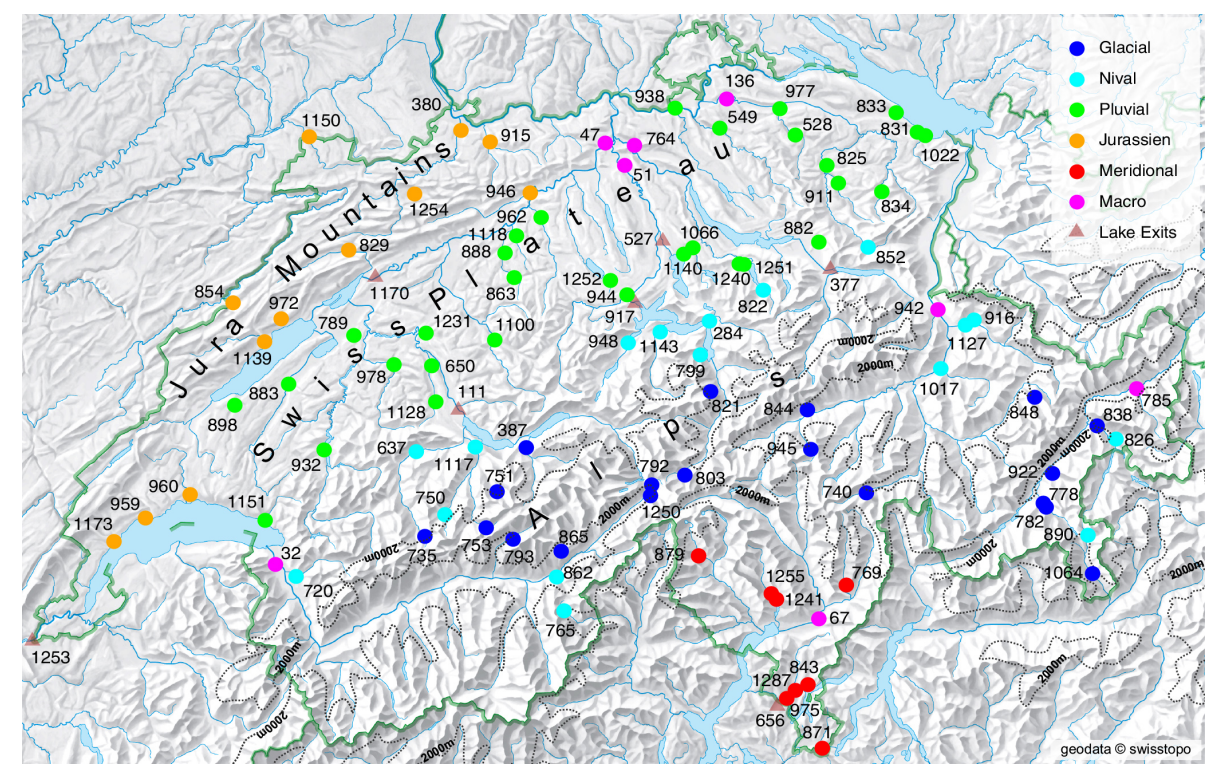

Figure 1. Swiss river discharge stations selected for this study. Colors refer to the hydrological regimes in the legend. Stations at lake outlets are shown by triangles to highlight the strong anthropogenic influence on the discharge (lake outlets are thus analyzed separately). The numbers refer to Table 3 which provide brief descriptions of the catchments.

The Swiss landscape contains distinct geographical and hydrological regions: The Alps (Prealps, High Alps, Southern Alps), the Swiss Plateau and the Jura Mountains. Each region shows specific hydro-meteorological properties. In order to account for this diversity, a typical hydrological regime has been attributed to each Micro and Meso catchment (see Fig. 1). This classification of hydrological regimes follows Aschwanden and Weingartner (1985); see also Weingartner and Aschwanden (1992). A first set of separation criteria is the mean elevation and the glacier coverage. These properties allow us to distinguish between Glacial (mean altitude $>1900 \mathrm{~m}$ and glacial coverage $>6 \%$ or mean altitude $>2300 \mathrm{~m}$ and glacial coverage $>1 \%$ ), Nival ( mean altitude $>1200 \mathrm{~m}$ ) and Pluvial regimes. The mean annual cycle of the runoff in Pluvial, Nival, and Glacial catchments is mainly dominated by rain water, snow melt, and glacier melt, respectively. Then, all catchments from the southern side of the Alps were joined in a separate group. The specific precipitation regime (Schmidli and Frei, 2005) and flood seasonality (Köplin et al., 2014) of this group, as well as the specific geology (crystalline, poor infiltration rates, steep slopes, and weak soils) motivated this choice. Aschwanden and Weingartner (1985) called this group "Meridional" to emphasize its southern location. Similarly, the catchments in the Jura Mountains were joined in the Jurassien regime type because of their shared specific morphology and geology (high plateaus, gentle slopes, high infiltration rates and important network of underground streams due to the calcareous and karstic bedrock).

From Glacial to Nival to Pluvial, the flood seasonality decreases but a maximum flood frequency in summer is main- tained. Meridional catchments are characterized by a maximum flood frequency in fall and summer and Jurassien catchments by winter floods with rain on snow as a major flood process (see e.g., Piock-Ellena et al., 2000; Köplin et al., 2014).

In summary, the different catchment subsamples are: Micro (52 catchments), Meso (35 catchments), Macro (8 catchments), Glacial (19 catchments), Nival (17 catchments), Pluvial (31 catchments), Meridional (8 catchments), Jurassien (12 catchments) and Lake Outlets (7 catchments). See Table 3 for a brief description of each catchment.

\subsection{Derivation of precipitation time series for each catchment}

We identified catchment area boundaries for each discharge station by applying a purely topography-based approach to a digital elevation model (DEM) with a $10 \mathrm{~m}$ resolution. For most of the Swiss territory, the effective drainage areas of the stations can be expected to be reasonably close to the catchments derived from the DEM. Critical regions are the highly karstic areas in the Jura Mountains and some areas of the Prealps, where the hydrological and topographical catchments tend to be significantly different because of the complex underground flow (see e.g., Malard and Jeannin, 2013). The most critical catchments were not considered for the analysis.

Area-averaged precipitation time series were obtained by combining the gridded precipitation data with the topographical catchment areas. 
Table 1. The different precipitation accumulation periods (PAPs) used in this study.

\begin{tabular}{llllll}
\hline D0-1 & climatological percentile of the & 2-days & precipitation sum & 0 to 1 days & before the flood day \\
D2-3 & climatological percentile of the & 2-days & precipitation sum & 2 to 3 days & before the flood day \\
D0-3 & climatological percentile of the & 4-days & precipitation sum & 0 to 3 days & before the flood day \\
D4-6 & climatological percentile of the & 3-days & precipitation sum & 4 to 6 days & before the flood day \\
D4-14 & climatological percentile of the & 11-days & precipitation sum & 4 to 14 days & before the flood day \\
D4-30 & climatological percentile of the & 27-days & precipitation sum & 4 to 30 days & before the flood day \\
D0-30 & climatological percentile of the & 31-days & precipitation sum & 0 to 30 days & before the flood day \\
API2 & climatological percentile of the & API & & 2 days & before the flood day \\
API4 & climatological percentile of the & API & & 4 days & before the flood day \\
PRE-AP & all precipitation accumulation periods excluding the last 3 days before the flood day (here D4-6, D4-14, D4-30 and API4) \\
\hline
\end{tabular}

\subsection{Definition of precipitation periods}

The first challenge is to distinguish between event and preevent precipitation. Flood triggering precipitation can be in the form of synoptically driven precipitation (periods lasting between a few hours to several days when the synoptic situation is particularly conducive to repeated precipitation events) and/or localized and short lived high precipitation events (typically convective). Ideally, a flood-by-flood analysis using a hydrological model should be performed to determine the exact time lag between the most intense precipitation rate and the discharge peak and to merge all precipitation events that can be attributed to a particular synoptic situation, such as the passage of a cyclone. However, a case-by-case analysis is beyond the scope of this study first because the daily resolution of the data does not allow for an evaluation of precipitation rates on sub daily timescales and second because of the very large number of events considered. Instead, we search for simple indices (precipitation accumulation periods, PAPs), that will (on average) best represent the precipitation associated with all floods in Swiss rivers.

A set of PAPs is defined (summarized in Table 1). Most PAPs represent a precipitation sum over a particular period before the flood day and two more PAPs are based on the concept of antecedent precipitation indices (API). A detailed description of the PAPs and the motivation for choosing them is given in Sect. 4.1. For example, PAP D4-14 is the precipitation sum that occurred within the period from 14 to 4 days prior to the flood day. PAPs are calculated for each day of the catchment-averaged precipitation time series (not only for flood days). The precipitation sums corresponding to flood days are then compared to the climatological distribution of all precipitation sums. The climatological sample is defined by a 3-month moving window centered on each day of the calendar year. For example, let us assume that a flood occurred on 1 June 2000. The D4-14 of that day is compared to all 11-day precipitation accumulations between 17 April and 16 July from 1979 to 2011 and the respective percentile of D4-14 is calculated. For each flood event we can thus determine the percentile value for each PAP. A 3-month moving window is an optimal compromise between minimizing the effects of precipitation seasonality and maximizing the climatological sample size (91 days per year times $20-50$ years means that each value is compared to $1820-4550$ other values).

Beside the simple precipitation sums, more complex indices for antecedent precipitation, i.e., APIs are used. APIs have been commonly used in hydrology for decades (see e.g., Kohler and Linsley Ray K., 1951; Pui et al., 2011). We follow the method of Baillifard et al. (2003):

$\mathrm{API}_{i}=P_{i}+K P_{i-1}+K^{2} P_{i-2}+\ldots+K^{n} P_{i-n}$,

where $P$ is the daily precipitation sum, $i$ is the day for which API is calculated, $K$ is the decay factor, and $n+1$ is the number of days since measurements began. Here, a constant $K$ value of 0.8 is used for all catchments. The decay factor $K$ is a proxy for diverse water fluxes that lead to a reduction of the water stored in a catchment. In this study, a decay rate of $20 \%$ per day, i.e., $K=0.8$, is chosen and reflects roughly typical conditions in Switzerland (Baillifard et al., 2003). Results are insensitive to a tested range of $K$ between 0.7 and 0.9. We use the indices API2 and API4 that include all days of the time series up to 2 and 4 days before the flood day (hereafter also called PAPs).

\subsection{Logistic regression}

The underlying hypothesis of this study is that, if a PAP is important for flood generation, a significant signal can be detected using the logistic regression. A lack of significance on the other hand, implies either that the PAP has no influence on flood probability or that this influence is too weak to be significant during the investigated period.

In Sect. 4.4 we assess the importance of the different PAPs for peak discharge generation at each catchment. A test is performed for each catchment and each PAP separately using a logistic regression model.

Binary daily time series of floods $y(t)$ and precipitation $\operatorname{PAP}_{T}(t)$ are calculated. The time series contain approximately 7000 to 18000 days $t$. For days when floods were recorded $y(t)=1$ and $y(t)=0$ for all other days. For days when the PAP exceeded a given percentile threshold $T$ 
$\operatorname{PAP}_{T}(t)=1$ and $\operatorname{PAP}_{T}(t)=0$ for all other days. The model is then fitted as follows:

$\operatorname{logit}(p(t))=\beta_{0}+\beta_{1} \operatorname{PAP}_{T}(t)$

where $\operatorname{logit}(x)=\log (x /(1-x))$, and $p(t)$ is the probability of observing a flood at day $t$ given the predictor, i.e., $p(t):=P\left(y(t)=1 \mid \mathrm{PAP}_{T}(t)\right)$.

We are particularly interested in the value of $\beta_{1}$. The odds ratio $\left(O=\exp \left(\beta_{1}\right)\right)$ is a measure for the increase (or decrease if $O$ is below 1$)$ of the odds, $p /(1-p)$, of a flood occurring when the PAP exceeds percentile $T$. Here, $p$ is by definition small (we look at yearly discharge maxima and even rarer events) and we can therefore set $p /(1-p) \approx p$ and the odds ratio can thus be understood as a multiplicative factor for the flood probability $p$. Statistical testing can assess the significance of the predictor $\mathrm{PAP}_{T}$.

A significant $p$ value implies that "the exceedance of a given precipitation threshold significantly changes the flood probability".

Note that working with binary predictors is not mandatory in logistic regression. Here this choice offers the advantage of avoiding the assumption that $\operatorname{logit}(p)$ is proportional to the percentile of the precipitation period; an assumption for which no particular argument could be found. A drawback is however that the regression can only be performed with predefined thresholds. Here, the logistic regressions are tested for five different thresholds (P50, P75, P90, P95, P99) and the $p$ value of the most significant test is selected (the corresponding thresholds and odd ratios are not discussed).

\section{Results}

Hereafter, we will use percentiles to describe precipitation quantities. To simplify the language, we define a set of expressions (see Table 2).

\subsection{Defining different precipitation periods preceding Swiss floods}

In order to determine the optimal separation of precipitation periods for the sample of events considered, the precipitation distribution is first investigated day by day. Figure $2 \mathrm{a}$ shows the distributions of daily precipitation sums for every day prior to and after all floods. For example, the boxplot at $x=-10$ represents the distribution of precipitation sums recorded 10 days before all floods (4257 values of daily precipitation recorded 10 days prior to the 4257 flood days). Moderate to high precipitation is most often recorded 1 day before floods when the 80th local seasonal percentile is exceeded in $75 \%$ of the cases and the median precipitation sum corresponds to the 98th climatological percentile. During flood days, the median precipitation only amounts to percentile 93 . The days -2 and -3 also show high precipitation sums with medians amounting to climatological
Table 2. Expressions used to define different quantities of precipitation.

\begin{tabular}{lll}
\hline Expression & Percentile & Return period \\
\hline Extreme & $>$ P99.9 & $>1000$ days \\
Very high & P99.9-P99 & $100-1000$ days \\
High & P99-P90 & $10-100$ days \\
Moderate & P90-P75 & 4-10 days \\
Unusually wet & $>$ P90 & $>10$ days \\
Wetter & $>$ P50 & $>2$ days \\
Drier & $<$ P50 & $<2$ days \\
\hline
\end{tabular}

percentiles 75 and 60, respectively. From day -4 backwards, the precipitation distribution is very close to climatology, although it tends to be slightly enhanced up to 10 to 15 days before floods. Similar results are observed when subsamples of catchments are analyzed (Fig. 2b-d). The maximum median daily precipitation is recorded $0-1$ days before HQ days at Micro catchments and 1-2 days before HQ days at Lake Outlets. A clearly enhanced median precipitation prior to 4 days before HQ days is only found at Lake Outlets.

Daily precipitation sums correspond to the 06:00 to 06:00 UTC accumulations and are therefore shifted by $5 \mathrm{~h}$ compared to discharge peaks recorded on calendar days. This partly explains the 1-day shift between maximum precipitation and HQ occurrence, especially for the floods in Micro catchments. The response time of catchments, i.e., the time between precipitation and registration of the related runoff at the gauge, plays a role as well. We therefore group the flood days and the preceding days together (hereafter the PAP called D0-1; see also Table 1). This is the time range when high precipitation quantities are most likely. As shown in Fig. 2b-c, this assumption is valid for Micro and Macro catchments whereas for Lake Outlets the highest precipitation occurs 2 days before floods (because of longer response times due to lake retention). Intense precipitation events responsible for flood peaks might be very short (hours or minutes in the case of flash floods) but the daily resolution of the data and the shift between precipitation and floods does not allow for a further separation of the time windows.

Precipitation 2 to 3 days before floods is also greater than climatology in all catchments and, interestingly, precipitation remains also greater than climatology 2 days after floods in Fig. 2a. An explanation for this phenomenon can be found in Fig. 2e, which shows the results of an analysis similar to the one of Fig. 2a but applied to maximum precipitation days instead of flood days. In Fig. 2e, the precipitation distribution is similarly enhanced \pm 2 days around high precipitation events like it is enhanced around flood events. The typical timescale of precipitating weather systems over Europe leads to some persistence of the daily weather situations so that daily precipitation time series are autocorrelated. Figure $2 \mathrm{a}$ thus highlights a time window centered between day -1 and day 0 and ranging from day -3 to day +2 when precipita- 

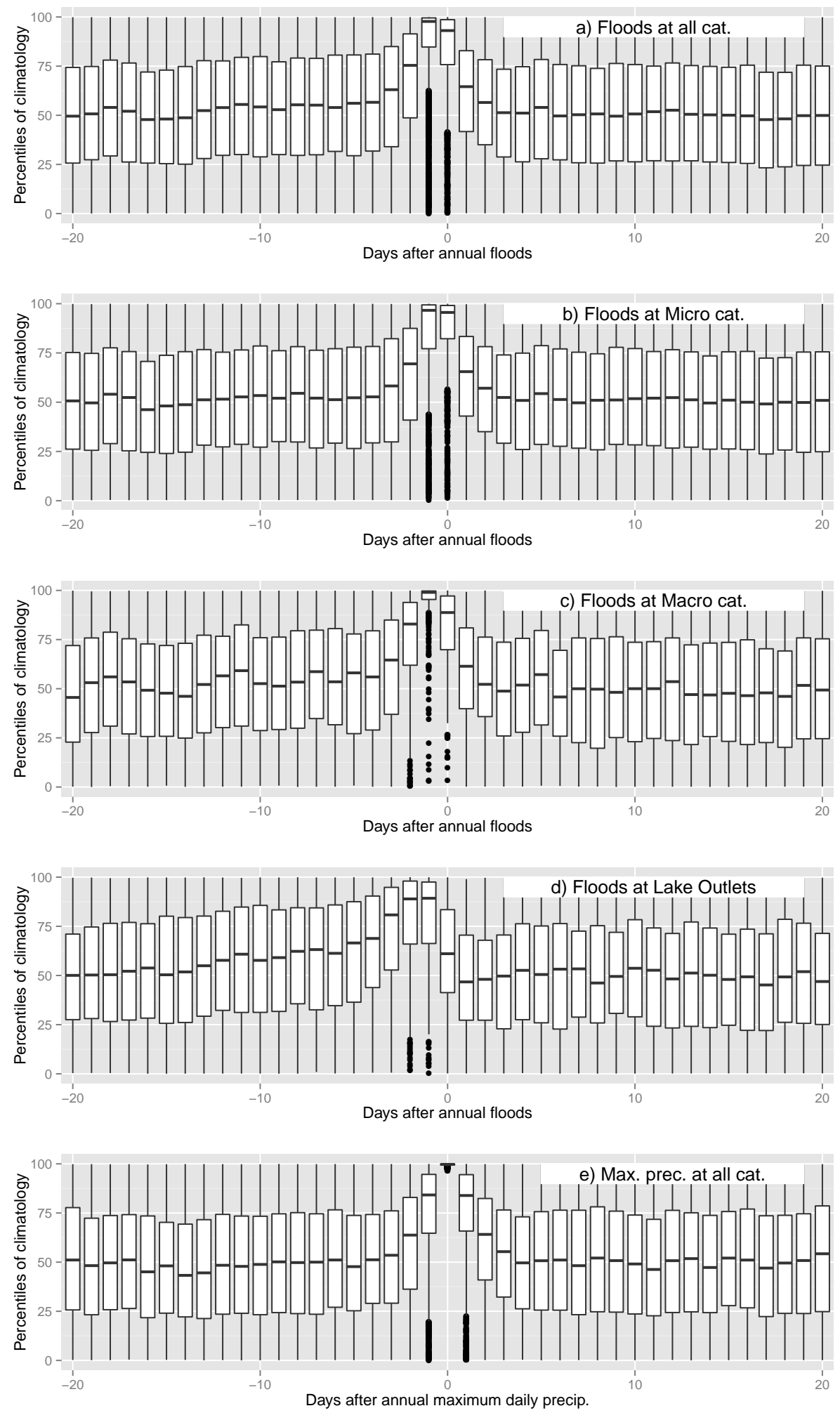

Figure 2. The distribution of daily precipitation before and after all flood events is shown in (a). For example, the boxplot at $x=-10$ represents the distribution of daily precipitation percentiles 10 days prior to the 4257 annual flood events analyzed in this study (all HQs from all catchments). The middle line of the boxplots shows the median, the boxes comprise the 25-75 percentile range, and the whiskers end at a deviation from the mean of 1.5 the interquartile range. (b)-(d) Same as (a) but for floods in Micro catchments, Macro catchments and Lake Outlets. (e) The same procedure as in (a), but applied to annual maximum precipitation days instead of annual flood days. 
Table 3. Summary of catchment properties for the selected stations. Catchments are sorted based on hydrological regime and increasing size from top to bottom. Locations are given in Swiss coordinates (CH1903).

\begin{tabular}{|c|c|c|c|c|c|c|c|c|}
\hline Number & Name & Coord. $x$ & Coord. $y$ & $\begin{array}{l}\text { Area } \\
{\left[\mathrm{km}^{2}\right]}\end{array}$ & $\begin{array}{r}\text { Station } \\
\text { height } \\
{[\mathrm{m}]}\end{array}$ & $\begin{array}{r}\text { Avg. } \\
\text { height } \\
{[\mathrm{m}]}\end{array}$ & $\begin{array}{l}\text { Glacier } \\
\text { coverage } \\
{[\%]}\end{array}$ & $\begin{array}{l}\text { Hydro. } \\
\text { regime }\end{array}$ \\
\hline 844 & Ferrerabach - Trun & 717795 & 179550 & 12.5 & 1220 & 2461 & 17.3 & Glacial \\
\hline 821 & Alpbach - Erstfeld, Bodenberg & 688560 & 185120 & 20.6 & 1022 & 2200 & 27.7 & Glacial \\
\hline 945 & Rein da Sumvitg - Sumvitg, Encardens & 718810 & 167690 & 21.8 & 1490 & 2450 & 6.7 & Glacial \\
\hline 751 & Gornernbach - Kiental & 624450 & 155130 & 25.6 & 1280 & 2270 & 17.3 & Glacial \\
\hline 838 & Ova da Cluozza - Zernez & 804930 & 174830 & 26.9 & 1509 & 2368 & 2.2 & Glacial \\
\hline 803 & Witenwasserenreuss - Realp & 680950 & 160130 & 30.7 & 1575 & 2427 & 12.7 & Glacial \\
\hline 735 & Simme - Oberried/Lenk & 602630 & 141660 & 35.7 & 1096 & 2370 & 34.6 & Glacial \\
\hline 792 & Rhone (Rotten) - Gletsch & 670810 & 157200 & 38.9 & 1761 & 2719 & 52.2 & Glacial \\
\hline 1250 & Goneri - Oberwald & 670520 & 153830 & 40 & 1385 & 2377 & 14.2 & Glacial \\
\hline 753 & Kander - Gasterntal, Staldi & 621080 & 144260 & 40.7 & 1470 & 2600 & 43.5 & Glacial \\
\hline 848 & Dischmabach - Davos, Kriegsmatte & 786220 & 183370 & 43.3 & 1668 & 2372 & 2.1 & Glacial \\
\hline 740 & Hinterrhein - Hinterrhein & 735480 & 154680 & 53.7 & 1584 & 2360 & 17.2 & Glacial \\
\hline 778 & Rosegbach - Pontresina & 788810 & 151690 & 66.5 & 1766 & 2716 & 30.1 & Glacial \\
\hline 922 & Chamuerabach - La Punt-Chamues-ch & 791430 & 160600 & 73.3 & 1720 & 2549 & 1.5 & Glacial \\
\hline 793 & Lonza - Blatten & 629130 & 140910 & 77.8 & 1520 & 2630 & 36.5 & Glacial \\
\hline 782 & Berninabach - Pontresina & 789440 & 151320 & 107 & 1804 & 2617 & 18.7 & Glacial \\
\hline 1064 & Poschiavino - Le Prese & 803490 & 130530 & 169 & 967 & 2170 & 6.5 & Glacial \\
\hline 865 & Massa - Blatten bei Naters & 643700 & 137290 & 195 & 1446 & 2945 & 65.9 & Glacial \\
\hline 387 & Lütschine - Gsteig & 633130 & 168200 & 379 & 585 & 2050 & 17.4 & Glacial \\
\hline 890 & Poschiavino - La Rösa & 802120 & 142010 & 14.1 & 1860 & 2283 & 0.35 & Nival \\
\hline 765 & Krummbach - Klusmatten & 644500 & 119420 & 19.8 & 1795 & 2276 & 3 & Nival \\
\hline 948 & Chli Schliere - Alpnach, Chilch Erli & 663800 & 199570 & 21.8 & 453 & 1370 & 0 & Nival \\
\hline 750 & Allenbach - Adelboden & 608710 & 148300 & 28.8 & 1297 & 1856 & 0 & Nival \\
\hline 799 & Grosstalbach - Isenthal & 685500 & 196050 & 43.9 & 767 & 1820 & 9.3 & Nival \\
\hline 826 & Ova dal Fuorn - Zernez, Punt la Drossa & 810560 & 170790 & 55.3 & 1707 & 2331 & 0.02 & Nival \\
\hline 822 & Minster - Euthal, Rüti & 704425 & 215310 & 59.2 & 894 & 1351 & 0 & Nival \\
\hline 916 & Taschinasbach - Grüsch Wasserf, Lietha & 767930 & 206420 & 63 & 666 & 1768 & 0.04 & Nival \\
\hline 862 & Saltina - Brig & 642220 & 129630 & 77.7 & 677 & 2050 & 5.1 & Nival \\
\hline 852 & Thur - Stein, Iltishag & 736020 & 228250 & 84 & 850 & 1448 & 0 & Nival \\
\hline 720 & Grande Eau - Aigle & 563975 & 129825 & 132 & 414 & 1560 & 1.8 & Nival \\
\hline 1143 & Engelberger Aa-Buochs, Flugplatz & 673555 & 202870 & 227 & 443 & 1620 & 4.3 & Nival \\
\hline 1017 & Plessur - Chur & 757975 & 191925 & 263 & 573 & 1850 & 0 & Nival \\
\hline 284 & Muota - Ingenbohl & 688230 & 206140 & 316 & 438 & 1360 & 0.08 & Nival \\
\hline 637 & Simme - Oberwil & 600060 & 167090 & 344 & 777 & 1640 & 3.7 & Nival \\
\hline 1117 & Kander - Hondrich & 617790 & 168400 & 496 & 650 & 1900 & 7.9 & Nival \\
\hline 1127 & Landquart - Felsenbach & 765365 & 204910 & 616 & 571 & 1800 & 1.4 & Nival \\
\hline 1252 & Sellenbodenbach - Neuenkirch & 658530 & 218290 & 10.5 & 515 & 615 & 0 & Pluvial \\
\hline 882 & Steinenbach - Kaltbrunn, Steinenbrugg & 721215 & 229745 & 19.1 & 451 & 1112 & 0 & Pluvial \\
\hline 831 & Steinach - Steinach & 750760 & 262610 & 24.2 & 406 & 710 & 0 & Pluvial \\
\hline 1240 & Biber - Biberbrugg & 697240 & 223280 & 31.9 & 825 & 1009 & 0 & Pluvial \\
\hline 932 & Sionge - Vuippens, Château & 572420 & 167540 & 45.3 & 681 & 862 & 0 & Pluvial \\
\hline 1251 & Alp - Einsiedeln & 698640 & 223020 & 46.4 & 840 & 1155 & 0 & Pluvial \\
\hline 833 & Aach - Salmsach, Hungerbühl & 744410 & 268400 & 48.5 & 406 & 480 & 0 & Pluvial \\
\hline 1022 & Goldach - Goldach & 753190 & 261590 & 49.8 & 399 & 833 & 0 & Pluvial \\
\hline 789 & Bibere - Kerzers & 581280 & 201850 & 50.1 & 443 & 540 & 0 & Pluvial \\
\hline 1118 & Rot - Roggwil & 630260 & 231650 & 53.6 & 436 & 586 & 0 & Pluvial \\
\hline 1128 & Gürbe - Burgistein, Pfandersmatt & 605890 & 181880 & 53.7 & 569 & 1044 & 0 & Pluvial \\
\hline 863 & Langeten - Huttwil, Häberenbad & 629560 & 219135 & 59.9 & 597 & 766 & 0 & Pluvial \\
\hline 1231 & Worble - Ittigen & 603005 & 202455 & 60.5 & 522 & 679 & 0 & Pluvial \\
\hline 1151 & Veveyse - Vevey, Copet & 554675 & 146565 & 62.2 & 399 & 1108 & 0 & Pluvial \\
\hline
\end{tabular}


Table 3. Continued.

\begin{tabular}{|c|c|c|c|c|c|c|c|c|}
\hline Number & Name & Coord. $x$ & Coord. $y$ & $\begin{array}{l}\text { Area } \\
{\left[\mathrm{km}^{2}\right]}\end{array}$ & $\begin{array}{r}\text { Station } \\
\text { height } \\
{[\mathrm{m}]}\end{array}$ & $\begin{array}{r}\text { Avg. } \\
\text { height } \\
{[\mathrm{m}]}\end{array}$ & $\begin{array}{l}\text { Glacier } \\
\text { coverage } \\
{[\%]}\end{array}$ & $\begin{array}{l}\text { Hydro. } \\
\text { regime }\end{array}$ \\
\hline 834 & Urnäsch - Hundwil, Äschentobel & 740170 & 244800 & 64.5 & 747 & 1085 & 0 & Pluvial \\
\hline 528 & Murg - Wängi & 714105 & 261720 & 78.9 & 466 & 650 & 0 & Pluvial \\
\hline 1066 & Lorze - Baar & 683300 & 228070 & 84.7 & 455 & 866 & 0 & Pluvial \\
\hline 911 & Necker - Mogelsberg, Aachsäge & 727110 & 247290 & 88.2 & 606 & 959 & 0 & Pluvial \\
\hline 1140 & Lorze - Zug, Letzi & 680600 & 226070 & 101 & 417 & 825 & 0 & Pluvial \\
\hline 898 & Mentue - Yvonand, La Mauguettaz & 545440 & 180875 & 105 & 449 & 679 & 0 & Pluvial \\
\hline 888 & Langeten - Lotzwil & 626840 & 226535 & 115 & 500 & 713 & 0 & Pluvial \\
\hline 650 & Gürbe - Belp, Mülimatt & 604810 & 192680 & 117 & 522 & 837 & 0 & Pluvial \\
\hline 977 & Murg - Frauenfeld & 709540 & 269660 & 212 & 390 & 580 & 0 & Pluvial \\
\hline 549 & Töss - Neftenbach & 691460 & 263820 & 342 & 389 & 650 & 0 & Pluvial \\
\hline 978 & Sense - Thörishaus, Sensematt & 593350 & 193020 & 352 & 553 & 1068 & 0 & Pluvial \\
\hline 962 & Wigger - Zofingen & 637580 & 237080 & 368 & 426 & 660 & 0 & Pluvial \\
\hline 883 & Broye - Payerne, Caserne d'aviation & 561660 & 187320 & 392 & 441 & 710 & 0 & Pluvial \\
\hline 938 & Glatt - Rheinsfelden & 678040 & 269720 & 416 & 336 & 498 & 0 & Pluvial \\
\hline 1100 & Emme - Emmenmatt & 623610 & 200420 & 443 & 638 & 1070 & 0 & Pluvial \\
\hline 944 & Kleine Emme - Littau, Reussbühl & 664220 & 213200 & 477 & 431 & 1050 & 0 & Pluvial \\
\hline 825 & Thur - Jonschwil, Mühlau & 723675 & 252720 & 493 & 534 & 1030 & 0 & Pluvial \\
\hline 854 & Bied du Locle - La Rançonnière & 545025 & 211575 & 38 & 819 & NA & NA & Jurassien \\
\hline 1254 & Scheulte - Vicques & 599485 & 244150 & 72.8 & 463 & 785 & 0 & Jurassien \\
\hline 959 & Aubonne - Allaman, Le Coulet & 520720 & 147410 & 91.4 & 390 & 890 & 0 & Jurassien \\
\hline 1173 & Promenthouse - Gland, Route Suisse & 510080 & 140080 & 100 & 394 & 1037 & 0 & Jurassien \\
\hline 972 & Seyon - Valangin & 559370 & 206810 & 112 & 630 & 970 & 0 & Jurassien \\
\hline 829 & Suze - Sonceboz & 579810 & 227350 & 150 & 642 & 1050 & 0 & Jurassien \\
\hline 946 & Dünnern - Olten, Hammermühle & 634330 & 244480 & 196 & 400 & 750 & 0 & Jurassien \\
\hline 1150 & Allaine - Boncourt, Frontière & 567830 & 261200 & 215 & 366 & 559 & 0 & Jurassien \\
\hline 960 & Venoge - Ecublens, Les Bois & 532040 & 154160 & 231 & 383 & 700 & 0 & Jurassien \\
\hline 915 & Ergolz - Liestal & 622270 & 259750 & 261 & 305 & 590 & 0 & Jurassien \\
\hline 1139 & Areuse - Boudry & 554350 & 199940 & 377 & 444 & 1060 & 0 & Jurassien \\
\hline 380 & Birs - Münchenstein, Hofmatt & 613570 & 263080 & 911 & 268 & 740 & 0 & Jurassien \\
\hline 879 & Riale di Calneggia - Cavergno, Pontit & 684970 & 135960 & 24 & 890 & 1996 & 0 & Meridional \\
\hline 975 & Magliasina - Magliaso, Ponte & 711620 & 93290 & 34.3 & 295 & 920 & 0 & Meridional \\
\hline 1255 & Riale di Pincascia - Lavertezzo & 708060 & 123950 & 44.4 & 536 & 1708 & 0 & Meridional \\
\hline 871 & Breggia - Chiasso, Ponte di Polenta & 722315 & 78320 & 47.4 & 255 & 927 & 0 & Meridional \\
\hline 843 & Cassarate - Pregassona & 718010 & 97380 & 73.9 & 291 & 990 & 0 & Meridional \\
\hline 1287 & Vedeggio - Agno & 714110 & 95680 & 105 & 281 & 898 & 0 & Meridional \\
\hline 769 & Calancasca - Buseno & 729440 & 127180 & 120 & 746 & 1950 & 1.1 & Meridional \\
\hline 1241 & Verzasca - Lavertezzo, Campiòi & 708420 & 122920 & 186 & 490 & 1672 & 0 & Meridional \\
\hline 67 & Ticino - Bellinzona & 721245 & 117025 & 1515 & 220 & 1680 & 0.7 & Macro \\
\hline 785 & Inn - Tarasp & 816800 & 185910 & 1584 & 1183 & 2390 & 5.1 & Macro \\
\hline 136 & Thur - Andelfingen & 693510 & 272500 & 1696 & 356 & 770 & 0 & Macro \\
\hline 764 & Limmat - Baden, Limmatpromenade & 665640 & 258690 & 2396 & 351 & 1130 & 1.1 & Macro \\
\hline 51 & Reuss - Mellingen & 662830 & 252580 & 3382 & 345 & 1240 & 2.8 & Macro \\
\hline 942 & Rhein - Bad Ragaz, ARA & 757090 & 209600 & 4455 & 491 & 1930 & 1.9 & Macro \\
\hline 32 & Rhône - Porte du Scex & 557660 & 133280 & 5244 & 377 & 2130 & 14.3 & Macro \\
\hline 47 & Aare - Brugg & 657000 & 259360 & 11726 & 332 & 1010 & 2 & Macro \\
\hline 527 & Lorze - Frauenthal & 674715 & 229845 & 259 & 390 & 690 & 0 & Lake Outlet \\
\hline 656 & Tresa - Ponte Tresa, Rocchetta & 709580 & 92145 & 615 & 268 & 800 & 0 & Lake Outlet \\
\hline 377 & Linth - Weesen, Biäsche & 725160 & 221380 & 1061 & 419 & 1580 & 2.5 & Lake Outlet \\
\hline 917 & Reuss - Luzern, Geissmattbrücke & 665330 & 211800 & 2251 & 432 & 1500 & 4.2 & Lake Outlet \\
\hline 111 & Aare - Thun & 613230 & 179280 & 2466 & 548 & 1760 & 9.5 & Lake Outlet \\
\hline 1253 & Rhône - Genève, Halle de l'Ile & 499890 & 117850 & 7987 & 369 & 1670 & 9.4 & Lake Outlet \\
\hline 1170 & Aare - Brügg, Ägerten & 588220 & 219020 & 8293 & 428 & 1150 & 2.9 & Lake Outlet \\
\hline
\end{tabular}



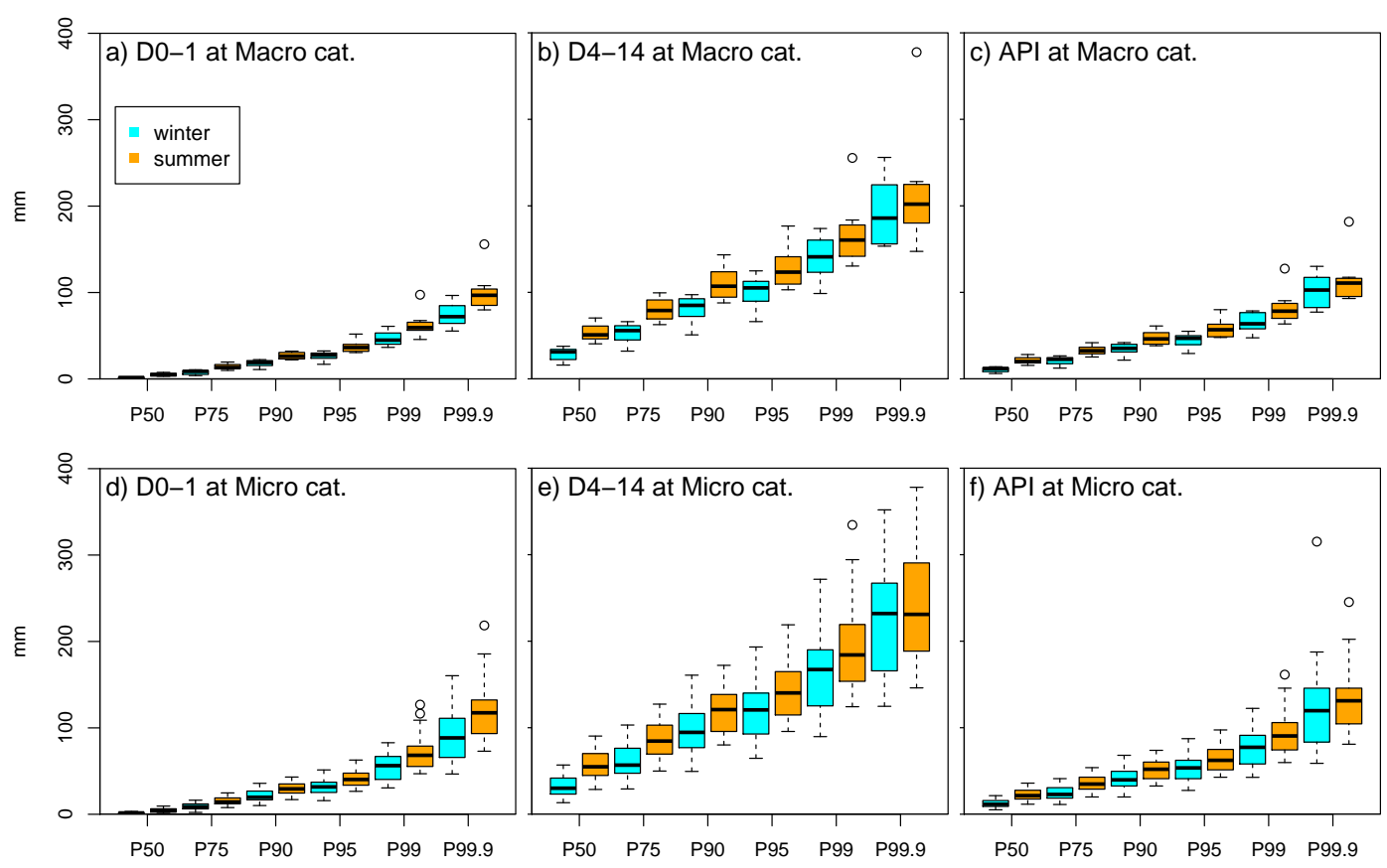

Figure 3. Absolute values of the climatological percentiles for the different PAPs. Statistics from Macro (a-c) and Micro (d-f) catchments are shown on the top and bottom row, respectively. Accumulations over 2 days which correspond to the PAPs D0-1 or D2-3 are shown in (a, d). Accumulations over 11 days corresponding to D4-14 are shown in (b, e). APIs are shown in (c, f). Variation between catchments is visualized in boxplots.

tion is clearly higher than usual. We identify it as the time range when the flood-producing weather situations generate high precipitation. Two more PAPs are thus defined which range back to 3 days before floods in order to capture precipitation associated with longer-lasting weather events (periods D0-3 and D2-3). The "precursor antecedent precipitation" (PRE-AP) is subsequently defined as the period finishing 4 days before floods. PAPs representing PRE-AP are D4-6, D4-14 and D4-30. To complete the set of PAPs, a similar separation is also applied to APIs (see API2 and API4, stopped 2 and 4 days before floods, respectively). Hereafter, the analysis is based on seasonal percentiles of the PAPs. For comparison, precipitation sums [mm] corresponding to percentiles of different PAPs are shown in Fig. 3. For example, the P99.9 of D0-1 in summer is summarized for all Macro catchments by the rightmost orange boxplot in Fig. 3a. The P99.9 exceeds $94 \mathrm{~mm}$ for $50 \%$ of the Macro catchments and reaches $156 \mathrm{~mm}$ at one catchment. The P99.9 of D0-1 at Macro catchments is in general lower in winter than in summer (compare the orange and the blue boxplot). Note that API2 and API4 result from the same calculation (see Eq. 1) applied at different days $i$. Their climatology is therefore the same and Fig. $3 \mathrm{c}$ and $\mathrm{f}$ are valid for both API2 and API4.

In hydrology, "antecedent precipitation" typically implies all the precipitation preceding the very last flood-triggering event. Here we separate flood-preceding precipitation into the short-range antecedent precipitation and what we define as the precursor antecedent precipitation PRE-AP. Although this sharp separation (between days -3 and -4 ) is only based on averaged statistics and although flood-triggering events can be defined over a wide range of timescales; we choose this simple formulation to distinguish explicitly long-range antecedent precipitation from a period when unusual precipitation is obvious in rainfall time series. We strongly emphasize that hereafter PRE-AP excludes the last 3 days before floods (see Table 1).

\subsection{Overview of the precipitation associated with Swiss floods}

We start the analysis with an overview of the variability of the precipitation associated with Swiss floods (event and preevent precipitation).

\subsubsection{The 2-day precipitation}

Figure 4 shows the 2-day PAP (D0-1) associated with each annual maximum discharge (HQ) of each catchment. The return periods of D0-1 vary by several orders of magnitude between different events. Very high precipitation (with a return period longer than 100 days) is frequently associated with floods, but a majority of catchments also experience HQs during low or moderate precipitation. A return period of D0-1 shorter than 10 days corresponds to a percentile lower than 90 and thus to less than $20-30 \mathrm{~mm}$ in 2 days (see Fig. 3a 


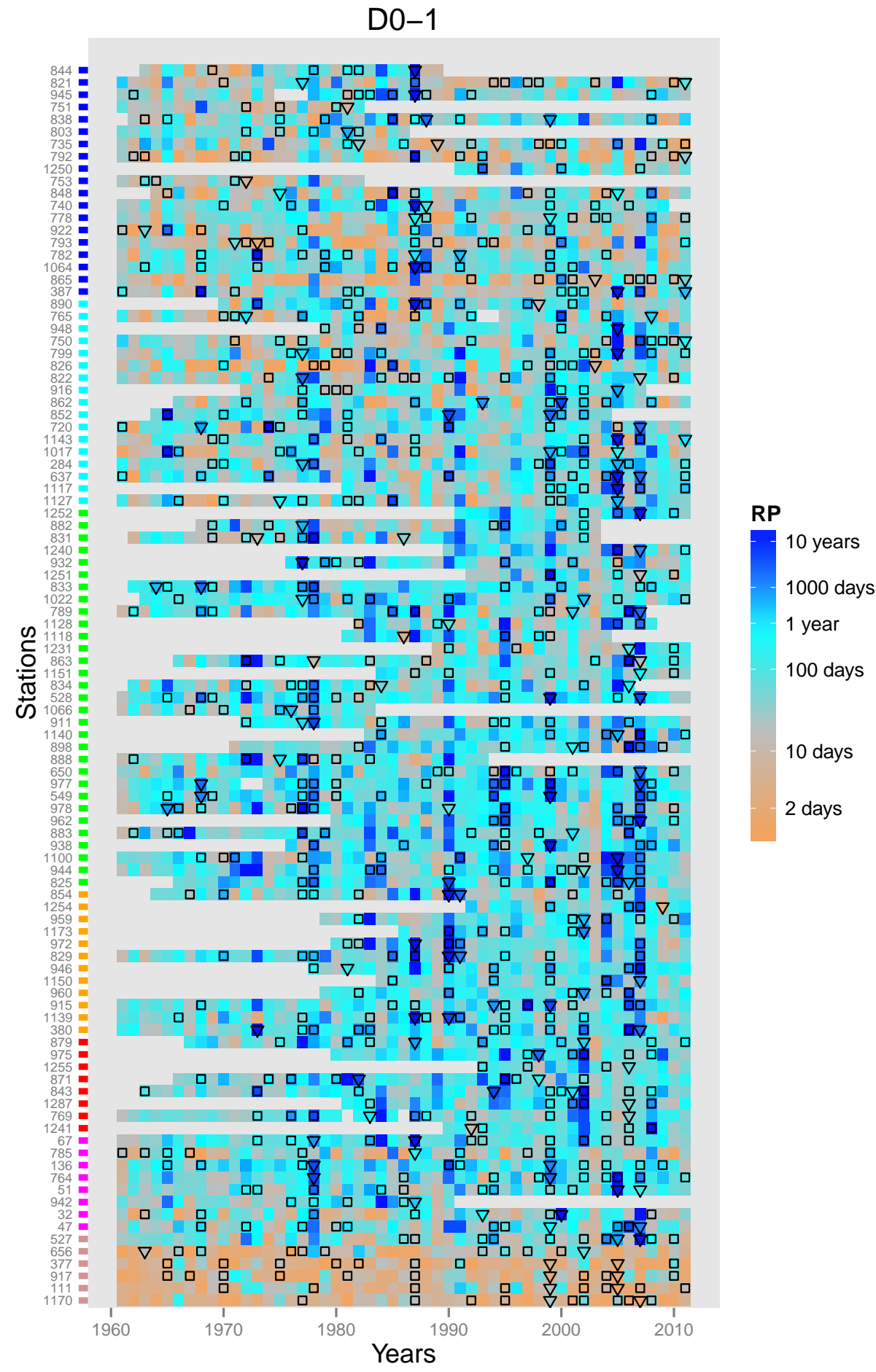

Figure 4. Overview of all flood events. All river discharge stations (numbers on the $y$ axis, see Table 3) cover at least 20 years in the 1961-2011 period. For each annual discharge peak, the return period of the 2-day precipitation sum (D0-1) is indicated by colors. HQ5s and HQ20s are marked with squares and triangles, respectively. The catchments are sorted by regime type and by increasing size from top to bottom. Hydrological regimes are indicated by colors: blue = Glacial, cyan = Nival, green = Pluvial, orange $=$ Jurassien, red $=$ Meridional, magenta $=$ Macro, brown $=$ Lake Outlets. 
and d). There are more floods without high D0-1 in Nival and Glacial regimes as compared to the Pluvial regime. The D01 in Jurassien and Meridional groups is comparable to the Pluvial group. D0-1 is slightly lower in Macro catchments and clearly the weakest for Lake Outlets. HQ5s and HQ20s tend to be associated with longer return periods of D0-1 than HQs, although they can also be triggered by weak or moderate precipitation (return periods shorter than 10 days), especially at Lake Outlets, as well as in Glacial and Nival catchments. Interestingly, extreme D0-1s often occur simultaneously in several catchments, indicating widespread events. Most of them correspond to extraordinary flood events in 1978, 1987, 1990, 1999, 2002, 2005, and 2007 and involve several HQ20s.

\subsubsection{Precursor antecedent precipitation}

Figure 5 is similar to Fig. 4 but shows the PAP D4-14, i.e., the accumulated precipitation between day -4 and -14 (PRE-AP). The large majority of floods are associated with return periods of PRE-AP shorter than 10 days, i.e., not unusually wet. In general HQ5s and HQ20s are not associated with higher PRE-AP than HQs and the rare cases of unusually wet PRE-AP typically occur simultaneously at many catchments (like in 1972, 1993, 1999 and 2006).

The logarithmic scale of return periods in Figs. 4 and 5 underlines the fact that return periods of D4-14 are several orders of magnitude shorter than those of D0-1. However, one cannot expect D4-14 to be systematically extreme as this 11-day period often excludes the heavy precipitation (which happens just before the flood).

\subsection{Quantification of the precipitation during different periods preceding Swiss floods}

The overview of flood-precipitation in the last 50 years revealed that precipitation during PAP D0-1 was high or extreme for a majority of floods but PRE-AP (during PAP D414) was not. This raises the question of whether D4-14, although not extreme before floods, still tends to be wetter than climatology.

Figure 6 shows the distribution of PAPs for different flood samples (deviations from climatology significant at the $99 \%$ level are outside of the gray zones). The gray zones are based on binomial distributions and represent the $99 \%$ level of significance of the variations of relative frequency in case of independent events. In the case investigated, the independence of events cannot be assessed in a purely quantitative way but the flood events are likely dependent, i.e., there are more simultaneous flood occurrences than expected from a random process, because floods in neighboring catchments can be triggered by the same weather event. The significance shown is hence likely too high (the zones too small) but the gray zones are still drawn as indicators of the minimum amount of random noise that can be expected. Note that it is strongly dependent on the sample size, i.e., on the number of flood events.

For HQ5s in Micro catchments (Fig. 6a), precipitation during D0-1 was very high (higher than P99) for $61 \%$ of the floods and high (higher than P90) for $90 \%$ of the events. Only $10 \%$ of the floods were preceded by no or moderate precipitation (lower than P90). For D2-3, high and very high precipitation was also significantly more frequent than usual although the deviation from climatology is very weak compared to D0-1. Drier percentiles of D2-3 were also significantly less frequent than usual (only $35 \%$ of the cases are below P50). On the other hand, no significant departure from climatology is found for the PRE-AP PAPs (D4-6, D4-14, D4-30). This means that, as a general rule, the conditions were not significantly wetter than usual earlier than 3 days before floods in Micro catchments.

The statistics of Meso and Macro catchments (Fig. 6b-c) resemble the ones of Micro catchments.

In contrast, HQ5s at Lake Outlets (Fig. 6d) were triggered by significantly higher than usual precipitation during all PAPs (and not only during D0-1 and D2-3). For example, a percentile of D4-14 higher than 99 is as frequently observed as a percentile lower than 50 .

Figure 6e-f show the results for HQs and HQ20s in all catchments. During D0-1, very high precipitation is twice as frequent prior to HQ20s ( $80 \%$ of all floods) as it is prior to all annual HQs (45\% of all floods). However, the precipitation prior to HQs and HQ20s is surprisingly similar during the other periods (D2 -3 is only slightly higher for HQ20s than for HQs and PRE-AP is basically the same).

In summary, the flood events considered in this study, with the exception of Lake Outlets floods, frequently co-occur with high precipitation during the flood day and/or the day before (D0-1). Longer-lasting multi-day events also generate high precipitation during D2-3. The slightly larger departure from climatology during D2-3 at Macro compared to Micro catchments indicates a higher importance of longerlasting events. Helbling et al. (2006) already showed that larger catchments are more sensitive to longer-lasting precipitation at the sub-daily scale; here we can extend those findings to multi-day events. Regarding precipitation 4 or more days before HQ days, a significantly enhanced frequency of wet weeks is only found for Lake Outlets. For other catchments, floods did not happen after significantly wetter nor drier PRE-AP in general.

Although no significant signal is found, PRE-AP was nevertheless slightly wetter than climatology before floods in Switzerland. Consequently, more detailed analyses are presented in the next sections to explore the correlation between PRE-AP and floods for particular catchments, particular flood types, and particular flood seasons. 


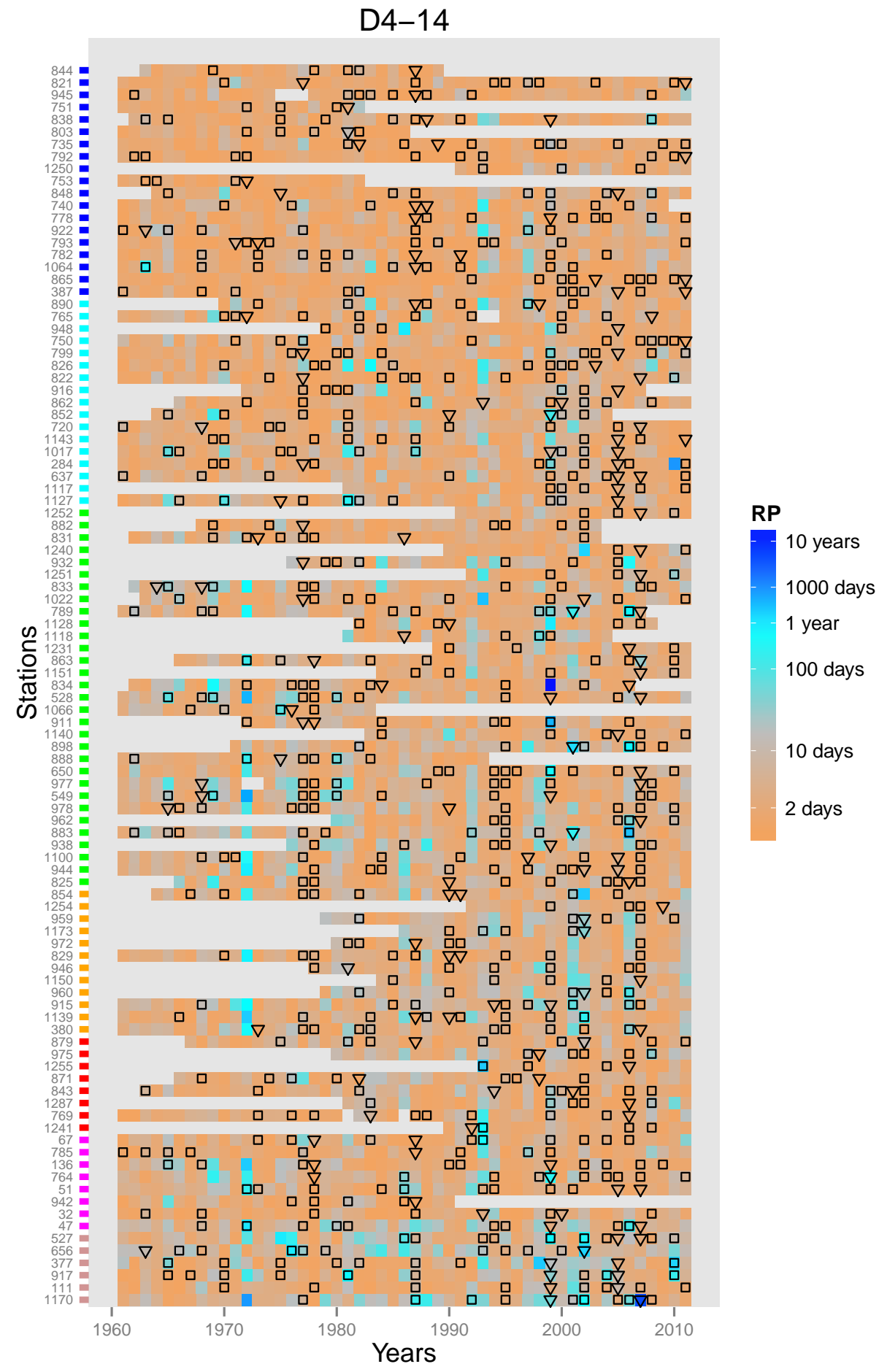

Figure 5. Same as Fig. 4 but for PRE-AP (D4-14).

\subsection{Catchment by catchment analysis}

Here, we use logistic regression to address the following question for each PAP and each catchment: is the occurrence of HQs influenced by the amount of precipitation? Or in other words: are floods more (or less) frequent after wet periods? We thereby aim to investigate whether the large variety of Swiss basins is associated with different flood responses to PAPs. Previous studies showed that typical floodtriggering precipitation depends not only on catchment size (investigated in the previous section), but also on various catchment properties (e.g., Merz and Blöschl, 2003; Wein- 

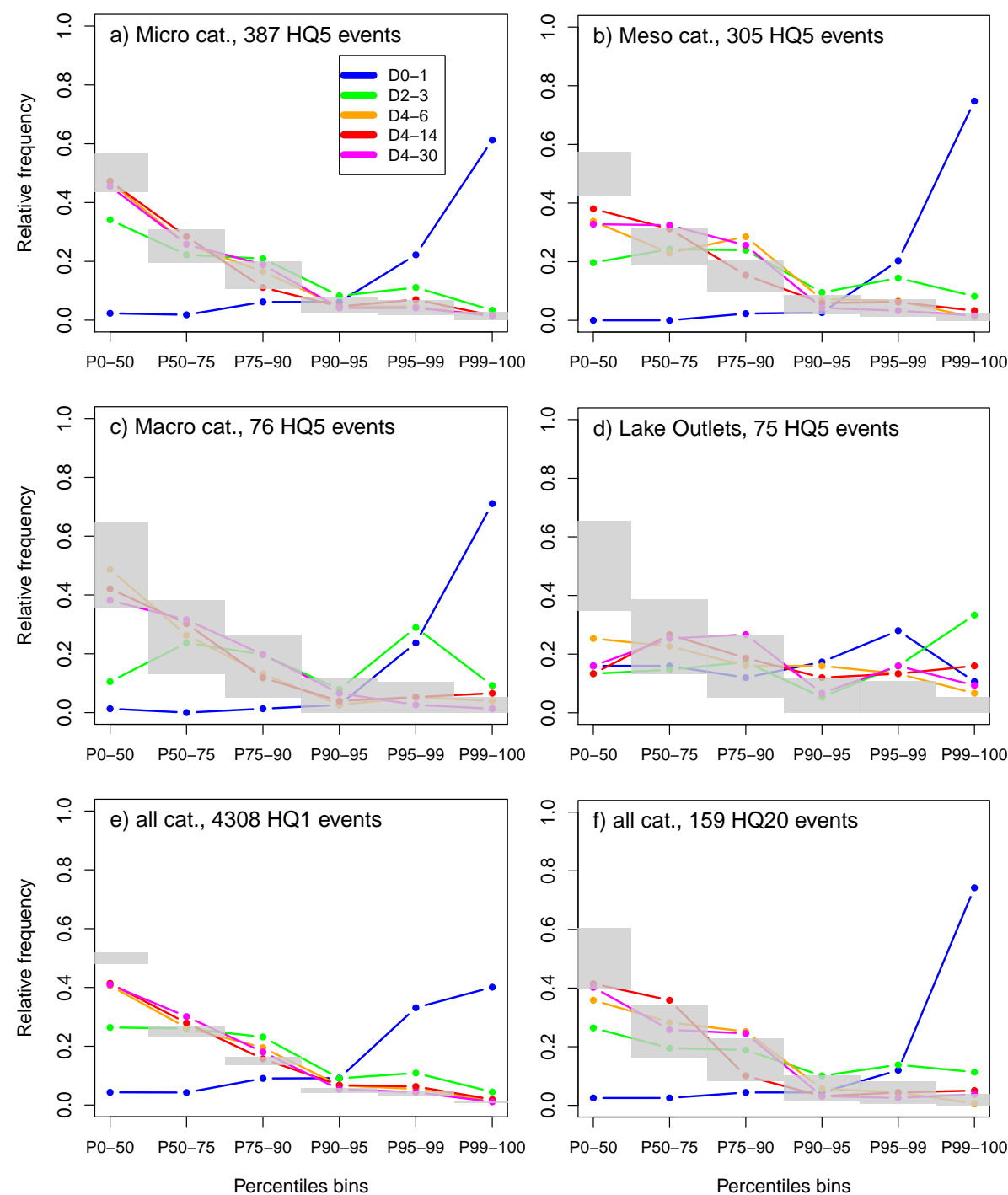

Figure 6. Relative frequency of precipitation percentiles for several PAPs before floods. Each colored line represents a PAP. (a)-(d) HQ5s in (a) Micro catchments, (b) Meso catchments, (c) Macro catchments and (d) Lake Outlets catchments. (e) All HQs and (f) HQ20s in all catchments. Gray shadings represent the $99 \%$ level of significance of the frequency of each percentile bin.

gartner et al., 2003; Helbling et al., 2006; Diezig and Weingartner, 2007). Potentially important properties include mean elevation, slope, land cover, soil type, geology and reservoirs (lakes, underground cavities). The hydrological regimes encompass some of this variability and serve as a framework for interpreting the following analysis.

Figure 7 shows the results of the logistic regression for the different PAPs (see details in Sect. 3.4). For example, triangles $(P$ value $<0.001)$ in Fig. 7a indicate that, in every catchment investigated, floods were significantly more frequent when a particular threshold of D0-1 was exceeded. In other words, the amount of precipitation that falls during D0-1 has a significant impact on flood frequency. The amount of precipitation that falls during D2-3 (Fig. 7b) also significantly impacts the flood frequency in most catchments, with the exception of most Glacial and few Nival and Pluvial catchments. With regard to PRE-AP in D4-6, D4-14 and D4-30 (Fig. 7c-e), clear regional patterns can be distinguished. Wet antecedent periods significantly enhance the flood frequency mainly in the northwest and northeast Switzerland, as well as at the outlet of all lakes except Lake Thun (no. 111). In contrast, floods were significantly less frequent after wet periods in some Glacial catchments. Indeed, six catchments show a significant $P$ value with an odd ratio smaller than 1 for D414. These are the exact six catchments with more than $25 \%$ glacial coverage. For the rest of Switzerland, the amount of PRE-AP does not significantly affect the flood probability. By comparing the results of D0-30 with D4-30, it emerges that floods are significantly associated with wet months (D030 ) in a large majority of catchments only because heavy pre- 

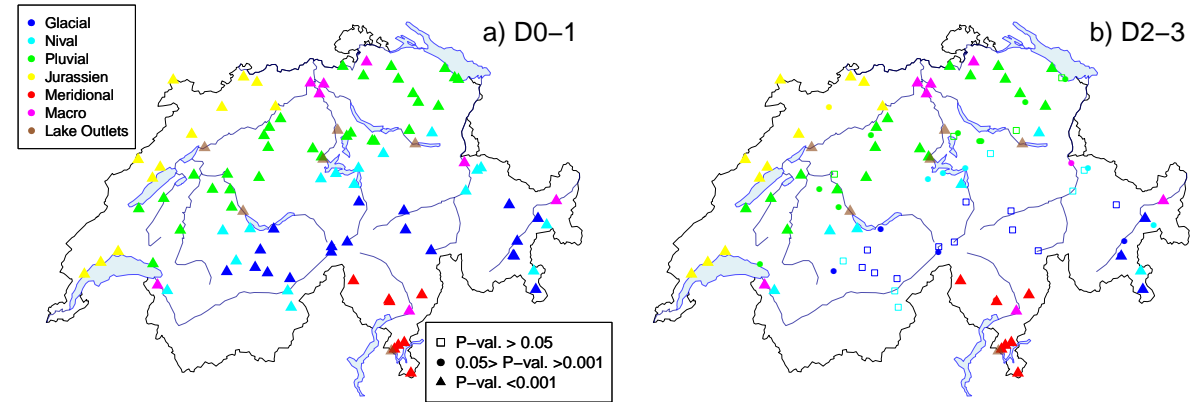

c) D4-6
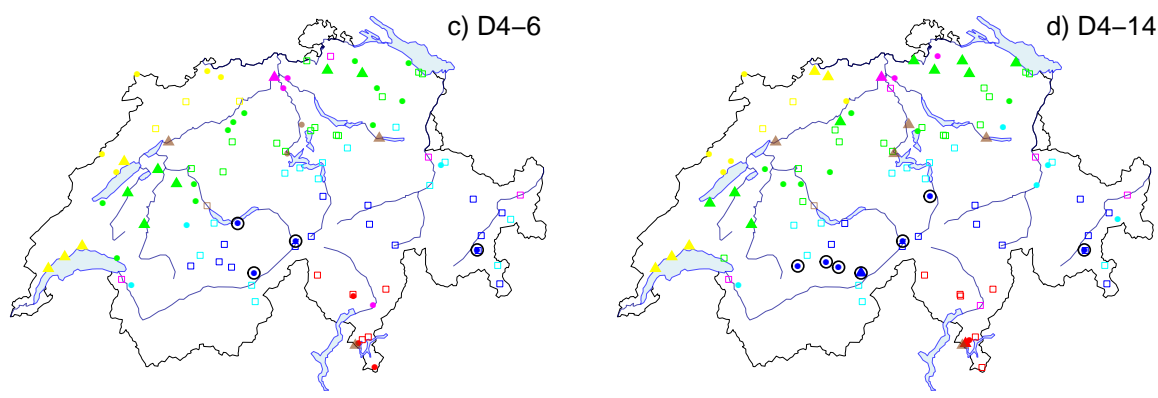

e) D4-30
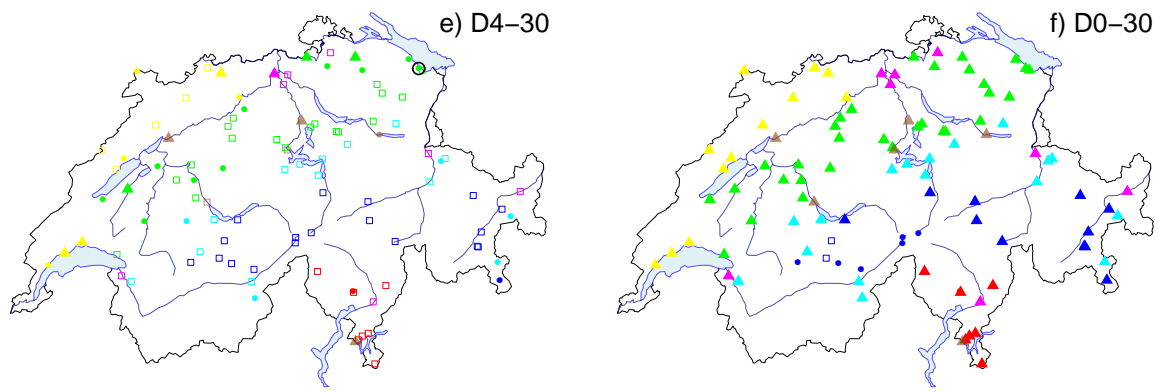

D0-30
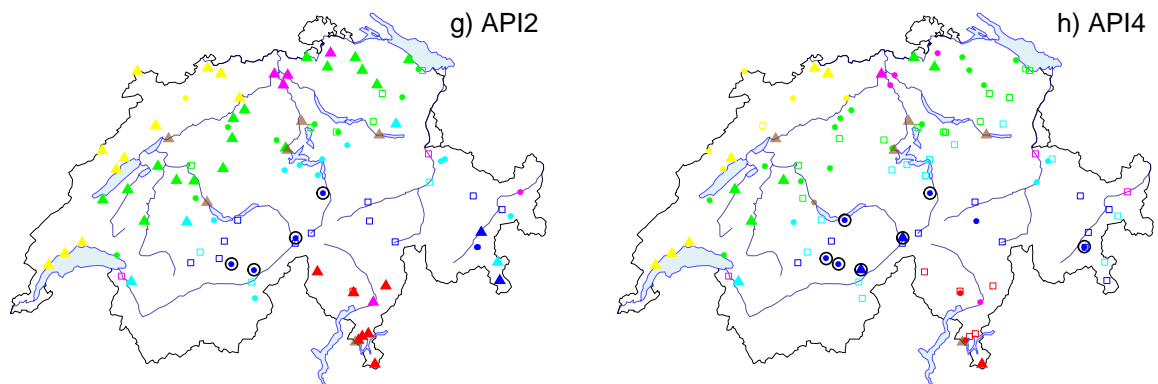

Figure 7. The relevance of the different precipitation periods for the occurrence of annual floods is tested using logistic regression for each precipitation period and each catchment (a) D0-1, (b) D2-3, (c) D4-6, (d) D4-14, (e) D4-30, (f) D0-30, (g) API2, and (h) API4. Several thresholds are tested (P50, P75, P90, P95, P99) and the most significant $P$ value is displayed symbolically (squares, dots and triangles indicate a non-, weakly-, and strongly significant influence, respectively). The colors of the symbols refer to the hydrological regimes of the catchments. Circles denote a negatively significant correlation, i.e., the exceedance of a given precipitation threshold significantly reduces flood probability.

cipitation 3-4 days before floods leads to high monthly accumulations. Indeed, D4-30 indicates that precipitation during the rest of the month has no significant impact on the flood probability for most catchments.

A reduced flood frequency following wet periods (like found for the glacial catchments) seems counterintuitive. The most significant negative correlation is found for the most glaciated catchment (the Aletsch glacier catchment, no. 865). The highest significance is obtained in this case with the threshold P75 because none of the $51 \mathrm{HQs}$ recorded correspond to the $25 \%$ wettest D4-14. The expected value is $51 / 4$; i.e., approximately $12-13 \mathrm{HQs}$. It is almost impossible to get 
0 HQs just by chance and an explanation must therefore be found. Glacial catchments are typically small and located at high elevations, exhibit steep slopes and lack deep soils. They are characterized by very short response times and a large runoff contribution from melt during the flood season (summer, see e.g., Verbunt et al., 2003; Köplin et al., 2014). The negative correlation is probably due to the fact that prolonged periods of wet weather (lower temperature, reduced sunshine and hence reduced melt) can lead to a lower baseflow in those catchments so that contributions from short and intense precipitation events would be less likely to generate annual discharge peaks. Indeed, discharge time series of glacial catchments are typically characterized by a pronounced diurnal cycle in summer, revealing the importance of high temperature and sunshine for melt and discharge generation. The baseflow continuously rises from day to day in case of extended periods of nice weather which are therefore particularly conducive to floods. Hence, floods are less frequent after precipitation at Glacial catchments, probably because of the reduced glacier melt.

Enhanced flood frequency after wet periods is less surprising. The Swiss Plateau, especially the western part, is a relatively flat area characterized by deep soils that need to be saturated before large runoff in the main streams is recorded. Soils in the Jura are typically thinner but very permeable and this region is well known for its underground karstic cavities. A karstic underground network can contain important reservoirs, the water level of which influences the flow response in surface streams (see e.g., Ball and Martin, 2012).

In summary, the role of long-term antecedent precipitation for flood generation depends strongly on the region and/or on the hydrological regime considered. Wet PRE-AP periods enhance HQ probability where soil saturation and reservoir filling are important processes and decrease HQ probability where melt water is an important contributor to the floods discharges.

\subsubsection{Antecedent precipitation indices (APIs)}

We also tested the power of APIs (see Table 1) for statistically predicting floods as compared to simple precipitation sums. API2, like D2-3, omits information about the flood day and the day preceding the flood but accounts for the whole antecedent precipitation instead of for only 2 days. The results for both periods are similar in most catchments. D2 -3 is a better (more significant) flood predictor than API2 for 12 catchments, and a weaker predictor for 11 catchments. API2 allows us to distinguish the relevance of dry periods for flooding in Glacial catchments but D2-3 is too short and too close to the flood to capture this signal. However, combining D2-3 and D4-6 indicates that dry conditions followed by wet conditions are important for flood formation in the Lütschine in Gsteig (no. 387), for example. Both periods cancel out in API2 and no significant signal is found. Searching for the best period also appears to be complex with regard to PRE-
AP. Each of the four periods (D4-6, D4-14, D4-30, API4) is the most significant flood predictor at several catchments. D4-30 is rarely the best predictor, indicating that the precipitation sum over a monthly period is not a powerful measure for flood probability. API 4 is slightly more often a better measure than D4-6 and D4-14, although this is not systematic. APIs are widely used in hydrology (see e.g., Kohler and Linsley Ray K., 1951; Fedora and Beschta, 1989; Heggen, 2001; Tramblay et al., 2012) but our integrative study cannot confirm that they explain flood frequency better than simple precipitation sums.

\subsection{Impacts of short-range precipitation and PRE-AP on flood magnitude}

In the previous sections, the impact of PAPs on HQ probability was discussed (i.e., whether floods are more frequent after wet periods). Here, the impact on the flood magnitude is investigated as well (i.e., whether larger floods follow wetter periods than smaller floods).

In Fig. 8, the flood-associated precipitation is simply summarized by the median return period of the PAPs for a flood sample. This allows us to compare various flood samples (different flood magnitudes, different catchment groups, different flood seasons). Assuming that the precipitation distribution is equal to climatology before floods, the median return period should be equal to 2 days (delimited by solid lines in the graphs).

For the Micro, Meso and Macro catchments in Fig. 8a, larger floods correspond to higher D0-1 than smaller floods (HQ20s are associated with a median return period of D0-1 of 400-1000 days $=1-3$ years while HQ1s correspond to a median D0-1 of only 60 days). In contrast, HQ20s are related to clearly higher D2-3 only at Macro catchments. At those catchments, as much precipitation falls 2 to 3 days before the HQ20s as falls 0 to 1 days before all HQs. At Lake Outlets, D2-3 is more extreme than D0-1 because of the long time delay between precipitation and gauged discharge (see Sect. 4.1).

Figure 8a can be directly compared to Fig. 8b. For Micro, Meso and Macro catchments, the return periods of D0-3 in Fig. $8 \mathrm{~b}$ are similar to the ones of $\mathrm{D} 0-1$. On the other hand, the median PRE-AP is remarkably close to normal for each catchment size (close to the climatological median). Moreover, the PRE-AP was not higher before HQ20s than before HQ1s. A change in PRE-AP with flood magnitude is only found at Lake Outlets.

Figure $8 \mathrm{c}-\mathrm{f}$ investigates different hydrological regimes and different flood seasons. For no regime and no season is the amount of PRE-AP precipitation linked to the flood amplitude. Even at Jurassien catchments, where we found that floods are significantly more frequent after wet periods, HQ20s are not associated with wetter periods than HQ1s. 

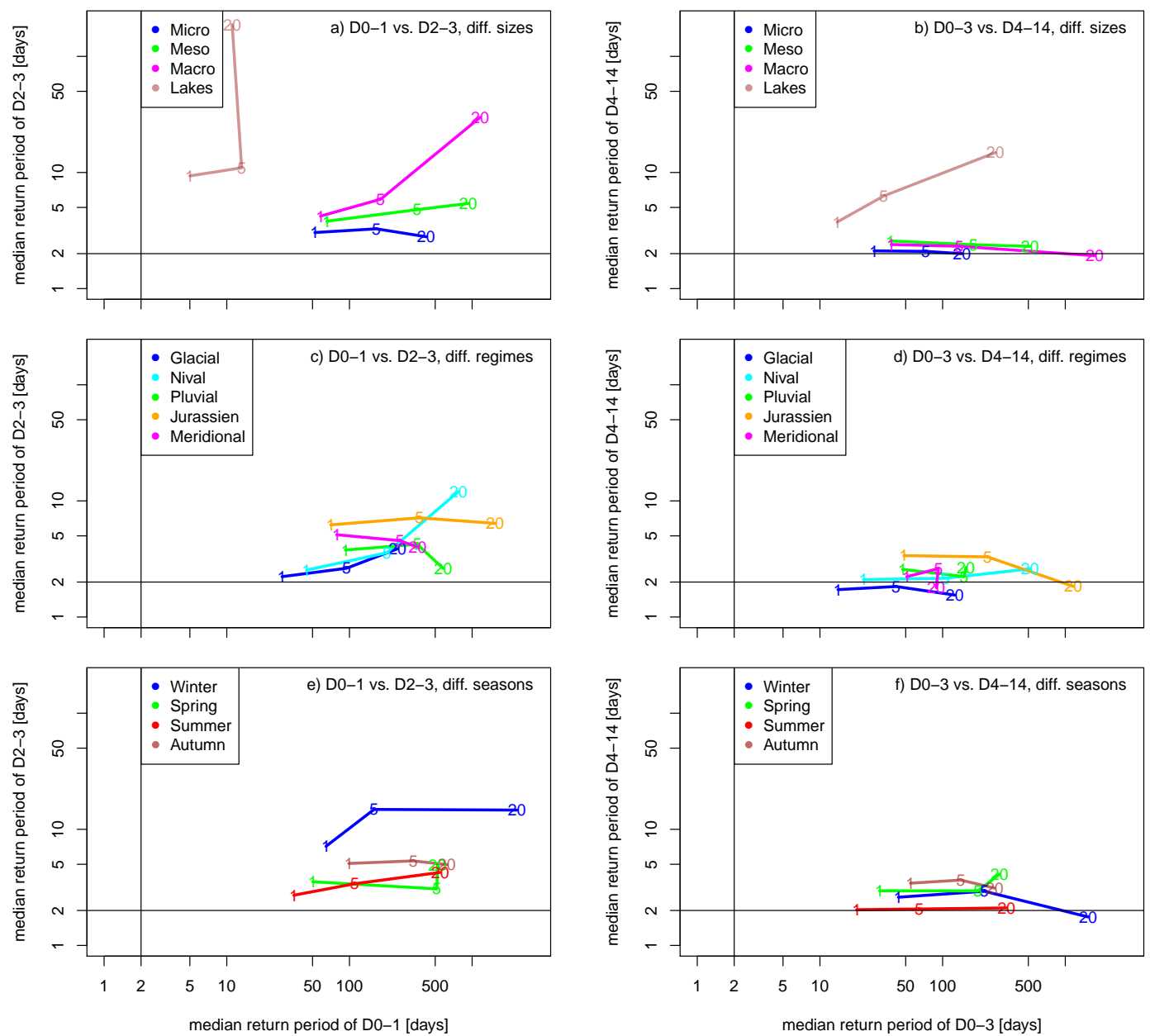

Figure 8. Median return periods of flood-associated precipitation for different flood samples. The rows show different catchment sizes (a, b), different hydrological regimes (c, d) and different flood seasons (e, f). The left column shows D0-1 in $x$ and D2-3 in $y$ and the right column D0-3 in $x$ and D4-14 in $y$. The numbers 1, 5 and 20 indicate median return periods associated with all HQs, with all HQ5s, and with all HQ20s, respectively. They are joined together by a line.

\subsection{Can weaker precipitation trigger floods if PRE-AP is higher?}

In the previous sections, the PAPs were investigated separately. Here we show the combinations of PRE-AP and shortrange precipitation events for single floods. If the runoff coefficient is enhanced by wetter PRE-AP (and thus more saturated soils), floods might happen in association with weaker triggering events.

Figure 9 shows D0-3 and D4-14 of all flood events for different catchment samples. As already inferred from Fig. 4, precipitation accumulations before floods vary remarkably between single events and the portion of floods lacking high triggering precipitation is highest in Glacial and $\mathrm{Ni}$ val catchments. The green lines in Fig. 9 show the linear regression between D0-3 and D4-14 for HQ5 events (only HQ5s are shown for clarity). The regression lines address the following question: did wet periods of PRE-AP allow weaker weather events to generate HQ5s? Indeed, it seems that for the Jurassien, Meridional and Lake Outlets catchments, HQ5s that were triggered by weaker weather events tend to be associated with higher values of PRE-AP. This is in contrast to Glacial catchments where weaker events trigger HQ5s after drier periods. Regarding flood forecasting, it would be interesting to define which minimum threshold of event precipitation is required to trigger a HQ5 given that PRE-AP is known, similarly to the flash flood guidance (FFG) approach (see e.g., Mogil et al., 1978). The scatter in observations shows that defining such a threshold is impossible for Switzerland because floods can occur in association with all types of precipitation. The only flood sample for which such a threshold would be realistic is the set of HQ20s at Lake Outlets. There, a HQ20 occurred without precipitation in the last 3 days but after an exceptionally wet period of PRE-AP. In contrast, all HQ20s occurring after not unusually wet periods of PRE-AP required at least a 

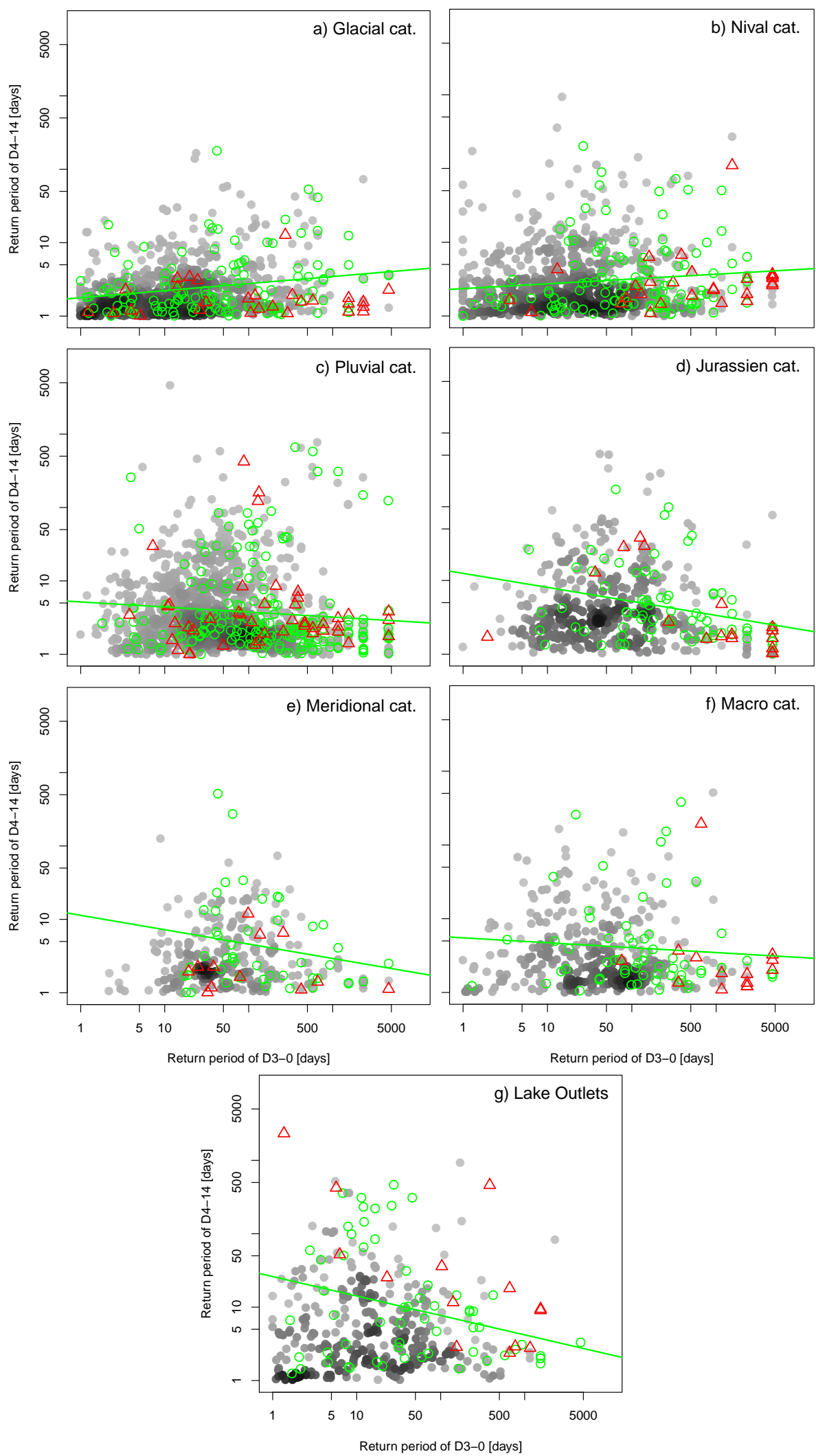

Figure 9. Flood-associated precipitation for different catchment samples: (a) Glacial, (b) Nival, (c) Pluvial, (d) Jurassien, (e) Meridional, (f) Macro and (g) Lake Outlets. For each discharge peak, D0-3 is shown in $x$ and D4-14 in $y$. Annual floods are shown by gray dots (shadings indicate the density of dots), HQ5s by green dots and HQ20s by red triangles. Green lines show the linear regression of the HQ5s. 
D0-3 of return period of 100 days. There might be a minimum threshold of D0-3 for HQ20s in Macro and Meridional catchments as well but it does not seem to depend on PREAP. The lack of a minimum threshold of D0-3 for floods is probably due to the very simple definition of precipitation used here and to the fact that the precipitation thresholds vary between catchments. Finer and catchment-specific approaches (see e.g., Norbiato et al., 2008) are required to formulate an FFG system for the catchments considered.

\section{Discussion}

A synoptic and statistical approach is used to separate event precipitation and antecedent precipitation for several thousands of floods. We define weekly to monthly precipitation periods preceding floods by more than 3 days "PREAP" (PREcursor Antecedent Precipitation) periods. Floodtriggering events are distinguished by $\mathrm{D} 0-1, \mathrm{D} 2-3$ and D03.

The relation between flood occurrence and the precipitation amount during D0-1 is stronger for Pluvial catchments than for Nival and Glacial catchments. We attribute this observation to the fact that rain-on-snow events are more common in Nival and Glacial catchments. During such events, the transformation of precipitation into runoff is strongly influenced by the presence of a snow cover through snow melt and complex snowpack runoff dynamics (see e.g., Wever et al., 2014). The Nival and Glacial catchments are also at higher altitudes and typically smaller than Pluvial catchments. They consequently react to shorter and more intense precipitation events which do not necessarily correspond to high 2-days sums.

We attribute the weak relationship between the precipitation amount during D0-1 and the occurrence of floods at lake outlets to the relatively strong influence of the PRE-AP. PRE-AP is indeed significantly related to flood occurrences at these catchments. This is most probably due to the large reservoir capacities of the lakes; i.e., the lakes must first be filled before floods can be recorded at their outlets.

The majority of the lake outlets is regulated. Small HQs after wet PRE-AP may be triggered by the lake regulation itself (if the gates are opened after long periods of precipitation resulting in high lake levels). However, we expect the extreme discharge peaks after wet PRE-AP to be damped due to the lake regulation. Despite the lake regulation, HQ20s at lake outlets are the floods that are proportionally the most frequent after wet PRE-AP. Lake regulation is often a compromise between the need to protect settlements adjacent to the lake but also the downstream areas; its effect on extreme floods is thus complex.

While PRE-AP is important at lake outlets, it is only weakly linked to flood probability at the other catchments and its influence is region-specific: (i) annual floods are significantly more frequent after wet PRE-AP periods in most
Jurassien catchments, in some Pluvial catchments of northwest and northeast Switzerland, and at lake outlets. (ii) Annual floods are significantly less frequent after wet PRE-AP periods in glacial catchments. (iii) The amount of PRE-AP is not significantly related to the occurrence of annual floods in the rest (the majority) of Swiss catchments. The fact that PRE-AP is only weakly related to floods compared to D0-1 or D0-3 is not astonishing. Indeed, we expected the highest precipitation amounts to fall during and just before the flood days, rather than 4 to 30 days before.

More unexpected is the fact that more precipitation during PRE-AP is, in the majority of catchments, not related to a significantly higher flood probability, nor to a higher flood amplitude. For most catchments, floods and precipitation amounts are not significantly related if we ignore precipitation during the last 4 days. This observation may be most convincingly reflected by Fig. $8 \mathrm{~b}$ which shows that the median PRE-AP of HQ20s is very close to the climatological median (except at lake outlets). The idea that the flood risk remains enhanced for several days after long periods of precipitation is strongly anchored in the general perception. The influence of soil saturation on runoff formation is indeed well established. Models showed that for the same triggering precipitation event, variations in antecedent moisture can lead to strong differences in discharge (see e.g., Berthet et al., 2009; Pathiraja et al., 2012). Also, artificial rainfall experiments showed that the runoff coefficient changes strongly with the amount of antecedent precipitation for various soil types in Switzerland (e.g., Spreafico et al., 2003). Moreover, weekly to monthly precipitation anomalies have been described as important factors for the development of extreme European floods (see e.g., Ulbrich et al., 2003; Grams et al., 2014; Schröter et al., 2015). Contrastingly, our results show that, in the majority of Swiss catchments and for the period investigated, flood days are not significantly different than other days regarding the amount of precipitation that fell earlier than 3 days before.

Our findings are, however, not in contradiction with the studies cited above. First, we find that the role of PRE-AP is very dependent on the hydrological regime of the catchments so that the absence of significant relationship between PRE$\mathrm{AP}$ and flood frequency/magnitude is specific to the Swiss Pre-Alpine, Alpine (except glaciers) and southern Alpine catchments. Second, several limitations inherent to the statistical experiment must be considered in order to correctly appreciate the results.

The statistical results do not mean that the runoff coefficient is independent of the amount of PRE-AP. Our analysis simply shows that this dependence is too weak to generate a significant signal when 20-50 floods per catchment are investigated. We nevertheless expect to be on the safe side when stating that PRE-AP has no significant influence on the flood occurrence at a particular catchment. Indeed, we performed 5 tests for each catchment and each PAP (we tested if the exceedance of the P50, P75, P90, P95 or P99 of the PAP 
significantly changes the flood probability). Significance was established even if only one of these five tests lead to a flood probability change with a $P$ value of $5 \%$.

Antecedent precipitation is not antecedent moisture. Extending the results to the role of antecedent moisture would require to use land surface models and/or extensive observations of soil moisture and ground water. This is beyond the scope of our study given the large number of events considered. We thus must emphasize that our results are limited to the role of antecedent precipitation amounts and that the moisture state may better represent the disposition of a catchment to generate discharge peaks, especially at the timescale covered by PRE-AP.

The small-scale temporal and spatial distribution of precipitation is an important determinant of the runoff coefficients of some catchments (e.g., Paschalis et al., 2014). Precipitation events can be very local and imply rapidly varying rainfall rates. Some short and/or localized precipitation events can thus be smoothed out or missed in the daily- and point measurement-based precipitation data set used here. The PAPs are with this regard very coarse representations of real precipitation events. While this limitation prevents us from describing the sub-daily flood-triggering precipitation characteristics, it is unlikely to impact the main findings of our study; namely the role of PRE-AP.

Finally, the PAPs have a constant formulation for all catchments, regardless of their diverse sizes and hydrological regimes. This limitation is inherent to the nature of the experiment. The consideration of more than 100 catchments and several thousands of discharge peaks limits obviously the possibilities of refinement. A catchment-specific formulation of the PAPs and the APIs (a calibration of the $K$ factor in Eq. (1) for e.g.) would allow for a finer distinction of the triggering events and the antecedent precipitation. Such a refinement would however require to determine typical response times for all catchments. Moreover, a dynamical formulation of PAPs and APIs would reduce the possibilities of comparing different catchment types. Instead, a strict and simple formulation of PAPs like the one used here maintains the experiment to an affordable level of complexity. This is in our opinion primordial when investigating very large samples.

Thanks to its relative simplicity, the method developed here can easily be used anywhere on the globe provided that extensive observations are available. Minimum requirements are multidecadal observations of discharge peaks and daily precipitation, as well as an accurate digital elevation model. The precipitation information may be the most critical to retrieve and potentially useful data sets must guarantee a sufficient homogeneity in space and time as well as a sufficient space resolution and coverage. The recent daily precipitation data set from Isotta et al. (2014) offers an interesting opportunity to extend the method developed here to the whole Alpine range. The high station density of the data set should also allow the analysis of Meso- to Micro-scale catchments. Over areas of sparse rain gauges networks, satellite or satellitegauge daily precipitation climatologies may alternatively be used (see e.g., Huffman et al., 2007).

\section{Conclusions}

We quantify statistically the influence of different precipitation periods for the generation of thousands of annual floods in Switzerland. In contrast to previous studies that define antecedent precipitation as all the water that fell before the very last flood-triggering precipitation event, we explicitly separate antecedent precipitation into the short-range and longrange antecedent precipitation based on the autocorrelation of daily precipitation time series and reflecting the synoptic timescale. The short-range encompasses the $0-3$ days period before floods and the long-range the earlier period (called PRE-AP). This novel distinction allows to specifically address the role of several antecedent precipitation periods for flood generation.

At the short range, we do not separate antecedent precipitation from the precipitation event directly triggering the discharge peak. Instead, we consider accumulations over several days and address the following question: over which preceding period is the amount of precipitation related to flood frequency and flood magnitude?

The 2-day sum ( $0-1$ days before floods) is clearly the best correlated with both the flood frequency and the flood magnitude. The precipitation 2 to 3 days before floods also significantly affects flood frequency everywhere except in the high Alps. It is moreover related to flood magnitude at lake outlets and in large catchments. Regarding earlier periods however, we find that PRE-AP has had no significant impact on flood frequency for the majority of Swiss catchments in the last 50 years. Moreover, the magnitude of floods was also independent of the magnitude of PRE-AP in all catchment types except at lake outlets. The influence of PRE-AP is thus weak overall. We thus suggest that researchers focus on 2 to 4 days precipitation periods when reconstructing antecedent precipitation of past Alpine floods or when inferring future Alpine flood risk from climate projections. Long-range antecedent precipitation periods preceding the last 3 days before floods are in contrast only relevant in the Jura Mountains, in the western and eastern Swiss Plateau, as well as at lake outlets. The results presented here may thus also motivate particular efforts to take benefit from information about the antecedent precipitation for flood warning in areas where antecedent precipitation significantly influences flood probability, given that these areas are not covered by more sophisticated deterministic flood warning systems.

Our findings are derived from extensive observations and can be expected to be robust and representative of the various flood types encountered in the Swiss territory. Although our results are specific to Swiss catchments, the method pre- 
sented here could be applied to other regions given that sufficient data are available.

The large differences in return periods of precipitation prior to floods of a similar magnitude indicate that catchment-averaged daily precipitation sums only explain a limited part of the flood variability. Future work is required to better characterize the short flood-triggering precipitation events at an hourly and a kilometer scale. The advent of a new gridded precipitation data set at an hourly resolution (combining rain gauges and radar) will offer new potential with this regard although the use of radar data to achieve this goal limits the time coverage to the 21 st century. This analysis may also be further expanded by including information about snow line, snow cover and soil moisture.

Acknowledgements. The authors gratefully acknowledge the Swiss Federal Office of the Environment (FOEN) for monitoring Swiss rivers, post-processing extreme discharge values and contributing to this study by providing data on annual maximum discharge events. This study would not have been possible without the high-end interpolation of rain gauges made available by the Swiss Federal Office of Meteorology (MeteoSwiss). We are thankful to Claudia Brauer and Massimiliano Zappa for their pertinent and constructive comments.

Edited by: A. Weerts

\section{References}

Aschwanden, H. and Spreafico, M.: Flood Discharge - Analysis of Long-Standing Measurement Series, Hydrological Atlas of Switzerland, http://hades.unibe.ch/en/products/druckausgabe/ gewaesser/tafe_15_06 (last access: 29 January 2015), 1995.

Aschwanden, H. and Weingartner, R.: Die Abflussregimes der Schweiz, Publikation Gewässerkunde Nr. 65, Geographisches Institut der Universität Bern, Bern, 237 pp., 1985.

Baillifard, F., Jaboyedoff, M., and Sartori, M.: Rockfall hazard mapping along a mountainous road in Switzerland using a GIS-based parameter rating approach, Nat. Hazards Earth Syst. Sci., 3, 435442, doi:10.5194/nhess-3-435-2003, 2003.

Ball, C. and Martin, J.: Spring Focus on Sustainability and the Environment: Effects of Antecedent Hydrogeologic Conditions on Flood Magnitude and Recharge to the Floridan Aquifer in NorthCentral Florida, J. Undergrad. Res., 13, 10 pp., 2012.

Barton, Y., Giannakaki, P., von Waldow, H., Chevalier, C., Pfahl, S., and Martius, O.: Clustering of Extreme Precipitation Events in Switzerland, Mon. Weather Rev., in review, 2014.

Berthet, L., Andréassian, V., Perrin, C., and Javelle, P.: How crucial is it to account for the antecedent moisture conditions in flood forecasting? Comparison of event-based and continuous approaches on 178 catchments, Hydrol. Earth Syst. Sci., 13, 819831, doi:10.5194/hess-13-819-2009, 2009.

Bezzola, G. and Hegg, C.: Ereignisanalyse Hochwasser 2005, Teil 1 - Prozesse, Schäden und erste Einordnung. Bundesamt für Umwelt BAFU, Eidgenössische Forschungsanstalt WSL, Umwelt-Wissen, 7, 215, http://www.bafu.admin.ch/ publikationen/publikation/00044/index.html?lang=de (last access: 29 January 2015), 2007.

CH2011: Swiss Climate Change Scenarios CH2011, published by C2SM, MeteoSwiss, ETH, NCCR Climate, and OcCC, Zurich, Switzerland, 88 pp., 2011.

Diezig, R. and Weingartner, R.: Hochwasserprozesstypen: Schlüssel zur Hochwasserabschätzung, Wasser und Abfall, 4, 18-26, 2007.

Fedora, M. A. and Beschta, R. L.: Storm runoff simulation using an antecedent precipitation index (API) model, J. Hydrol., 112, 121-133, doi:10.1016/0022-1694(89)90184-4, 1989.

Frei, C. and Schär, C.: A precipitation climatology of the Alps from high-resolution rain-gauge observations, Int. J. Climatol., 18, 873-900, doi:10.1002/(SICI)10970088(19980630)18:8<873::AID-JOC255>3.0.CO;2-9, 1998.

Grams, C. M., Binder, H., Pfahl, S., Piaget, N., and Wernli, H.: Atmospheric processes triggering the central European floods in June 2013, Nat. Hazards Earth Syst. Sci., 14, 1691-1702, doi:10.5194/nhess-14-1691-2014, 2014.

Gupta, H. V., Perrin, C., Blöschl, G., Montanari, A., Kumar, R., Clark, M., and Andréassian, V.: Large-sample hydrology: a need to balance depth with breadth, Hydrol. Earth Syst. Sci., 18, 463477, doi:10.5194/hess-18-463-2014, 2014.

Heggen, R. J.: Normalized Antecedent Precipitation Index, J. Hydrol. Eng., 6, 377-381, doi:10.1061/(ASCE)10840699(2001)6:5(377), 2001.

Helbling, A., Kan, C., and Vogt, S.: Dauerregen, Schauer oder Schmelze-welche Ereignisse lösen in der Schweiz die Jahreshochwasser aus?, Wasser Energie Luft, 98, 249-254, 2006.

Hilker, N., Badoux, A., and Hegg, C.: The Swiss flood and landslide damage database 1972-2007, Nat. Hazards Earth Syst. Sci., 9, 913-925, doi:10.5194/nhess-9-913-2009, 2009.

Hohenegger, C., Walser, A., Langhans, W., and Schär, C.: Cloudresolving ensemble simulations of the August 2005 Alpine flood, Q. J. Roy. Meteorol. Soc., 134, 889-904, doi:10.1002/qj.252, 2008.

Huffman, G. J., Bolvin, D. T., Nelkin, E. J., Wolff, D. B., Adler, R. F., Gu, G., Hong, Y., Bowman, K. P., and Stocker, E. F.: The TRMM multisatellite precipitation analysis (TMPA): Quasiglobal, multiyear, combined-sensor precipitation estimates at fine scales, J. Hydrometeorol., 8, 38-55, 2007.

Isotta, F. A., Frei, C., Weilguni, V., Perčec, Tadić, M., Lassègues, P., Rudolf, B., Pavan, V., Cacciamani, C., Antolini, G., Ratto, S. M., Munari, M., Micheletti, S., Bonati, V., Lussana, C., Ronchi, C., Panettieri, E., Marigo, G., and Vertačnik, G.: The climate of daily precipitation in the Alps: development and analysis of a highresolution grid dataset from pan-Alpine rain-gauge data, Int. J. Climatol., 34, 1657-1675, 2014.

Kohler, M. A. and Linsley Ray K.: Predicting The Runoff From Storm Rainfall, US Weather Bureau Research Paper, US Weather Bureau, US Deptartment of Commerce, Washington, 9 pp., 1951.

Köplin, N., Schädler, B., Viviroli, D., and Weingartner, R.: Seasonality and magnitude of floods in Switzerland under future climate change, Hydrol. Process., 28, 2567-2578, doi:10.1002/hyp.9757, 2014.

Liechti, K., Panziera, L., Germann, U., and Zappa, M.: The potential of radar-based ensemble forecasts for flash-flood early warning in the southern Swiss Alps, Hydrol. Earth Syst. Sci., 17, 38533869, doi:10.5194/hess-17-3853-2013, 2013. 
Malard, A. and Jeannin, P.-Y.: Characterisation of karst aquifers in Switzerland: the KARSYS approach, Eur. Geologist, 35, 59-63, 2013.

Marchi, L., Borga, M., Preciso, E., and Gaume, E.: Characterisation of selected extreme flash floods in Europe and implications for flood risk management, J. Hydrol., 394, 118-133, doi:10.1016/j.jhydrol.2010.07.017, 2010.

Massacand, A., Wernli, H., and Davies, H.: Heavy precipitation on the alpine southside: An upper-level precursor, Geophys. Res. Lett., 25, 1435-1438, doi:10.1029/98GL50869, 1998.

Merz, R. and Blöschl, G.: A process typology of regional floods, Water Resour. Res., 39, 1340, doi:10.1029/2002WR001952, 2003.

Merz, R. and Blöschl, G.: A regional analysis of event runoff coefficients with respect to climate and catchment characteristics in Austria, Water Resour. Res., 45, W01405, doi:10.1029/2008WR007163, 2009.

MeteoSwiss: Documentation of MeteoSwiss Grid-Data Products, Daily Precipitation (final analysis): RhiresD, http://www.meteoschweiz.admin.ch/home/suche.subpage.html/ de/data/products/2014/raeumliche-daten-niederschlag.html (last access: 29 January 2015), 2011.

Mogil, H. M., Monro, J. C., and Groper, H. S.: NWS's flash flood warning and disaster preparedness programs, B. Am. Meteorol. Soc., 59, 690-699, 1978.

Munich Re: NatCatSERVICE Database, Münchener Rückversicherungs-Gesellschaft, Munich, http://www.munichre. com/en/reinsurance/business/non-life/natcatservice/index.html (last access: 29 January 2015), 2014.

Norbiato, D., Borga, M., Degli Esposti, S., Gaume, E., and Anquetin, S.: Flash flood warning based on rainfall thresholds and soil moisture conditions: An assessment for gauged and ungauged basins, J. Hydrol., 362, 274-290, 2008.

Norbiato, D., Borga, M., Merz, R., Blöschl, G., and Carton, A.: Controls on event runoff coefficients in the eastern Italian Alps, J. Hydrol., 375, 312-325, doi:10.1016/j.jhydrol.2009.06.044, 2009.

Paschalis, A., Fatichi, S., Molnar, P., Rimkus, S., and Burlando, P.: On the effects of small scale space-time variability of rainfall on basin flood response, J. Hydrol., 514, 313-327, doi:10.1016/j.jhydrol.2014.04.014, 2014.

Pathiraja, S., Westra, S., and Sharma, A.: Why continuous simulation? The role of antecedent moisture in design flood estimation, Water Resour. Res., 48, W06534, doi:10.1029/2011WR010997, 2012.

Piock-Ellena, U., Pfaundler, M., Blöschl, G., Burlando, P., and Merz, R.: Saisonalitätsanalyse als Basis für die Regionalisierung von Hochwässern, Wasser Energie Luft, 92, 13-21, 2000.

Pui, A., Lal, A., and Sharma, A.: How does the Interdecadal Pacific Oscillation affect design floods in Australia?, Water Resour. Res., 47, W05554, doi:10.1029/2010WR009420, 2011.

Rajczak, J., Pall, P., and Schär, C.: Projections of extreme precipitation events in regional climate simulations for Europe and the Alpine Region, J. Geophys. Res.-Atmos., 118, 3610-3626, doi:10.1002/jgrd.50297, 2013.
Ranzi, R., Zappa, M., and Bacchi, B.: Hydrological aspects of the Mesoscale Alpine Programme: findings from field experiments and simulations, Q. J. Roy. Meteorol. Soc., 133, 867-880, doi:10.1002/qj.68, 2007.

Reager, J. T., Thomas, B. F., and Famiglietti, J. S.: River basin flood potential inferred using GRACE gravity observations at several months lead time, Nat. Geosci., 7, 588-592, doi:10.1038/ngeo2203, 2014.

Schmidli, J. and Frei, C.: Trends of heavy precipitation and wet and dry spells in Switzerland during the 20th century, Int. J. Climatol., 25, 753-771, doi:10.1002/joc.1179, 2005.

Schröter, K., Kunz, M., Elmer, F., Mühr, B., and Merz, B.: What made the June 2013 flood in Germany an exceptional event? A hydro-meteorological evaluation, Hydrol. Earth Syst. Sci., 19, 309-327, doi:10.5194/hess-19-309-2015, 2015.

Spreafico, R., Weingartner, R., Barben, M., Ryser, A., Hingray, B., Musy, A., and Niggli, M.: Hochwasserabschätzung in schweizerischen Einzugsgebieten, p. 117, http://www.bafu.admin.ch/ publikationen/publikation/00565/index.html?lang=de (last access: 29 January 2015), 2003.

Stucki, P., Rickli, R., Brönnimann, S., Martius, O., Wanner, H., Grebner, D., and Luterbacher, J.: Weather patterns and hydro-climatological precursors of extreme floods in Switzerland since 1868, Meteorol. Z., 21, 531-550, doi:10.1127/09412948/2012/368, 2012.

Tramblay, Y., Bouaicha, R., Brocca, L., Dorigo, W., Bouvier, C., Camici, S., and Servat, E.: Estimation of antecedent wetness conditions for flood modelling in northern Morocco, Hydrol. Earth Syst. Sci., 16, 4375-4386, doi:10.5194/hess-16-43752012, 2012.

Ulbrich, U., Brücher, T., Fink, A., Leckebusch, G., Krüger, A., and Pinto, J.: The central European floods of August 2002: Part 2 - Synoptic causes and considerations with respect to climatic change, Weather, 58, 434-442, doi:10.1256/wea.61.03B, 2003.

Verbunt, M., Gurtz, J., Jasper, K., Lang, H., Warmerdam, P., and Zappa, M.: The hydrological role of snow and glaciers in alpine river basins and their distributed modeling, J. Hydrol., 282, 3655, doi:10.1016/S0022-1694(03)00251-8, 2003.

Weingartner, R. and Aschwanden, H.: Discharge regime - the Basis for the Estimation of Average Flows, http://hades.unibe.ch/en/ products/druckausgabe/gewaesser/tafel5_02 (last access: 29 January 2015), 1992.

Weingartner, R., Barben, M., and Spreafico, M.: Floods in mountain areas - an overview based on examples from Switzerland, J. Hydrol., 282, 10-24, doi:10.1016/S0022-1694(03)00249-X, 2003.

Wever, N., Jonas, T., Fierz, C., and Lehning, M.: Model simulations of the modulating effect of the snow cover in a rain-on-snow event, Hydrol. Earth Syst. Sci., 18, 4657-4669, doi:10.5194/hess-18-4657-2014, 2014.

De Wit, M. and Buishand, A.: Generator of rainfall and discharge extremes (GRADE) for the Rhine and Meuse basins, Rijkswaterstaat RIZA Report 2007, 027/KNMI publication 218, Lelystad, 2007. 